\title{
New insights on manipulating the material removal characteristics of Jet-Electrochemical machining through nozzle design
}

\author{
Thomas Kendall $^{1}$ (1) $\cdot$ Carl Diver $^{2} \cdot$ David Gillen $^{3} \cdot$ Paulo Bartolo $^{1}$ \\ Received: 4 February 2021 / Accepted: 21 July 2021 / Published online: 12 September 2021 \\ (C) The Author(s) 2021
}

\begin{abstract}
Jet-Electrochemical machining (Jet-ECM) is a novel variation of traditional electrochemical machining in which electrically conductive material is removed through anodic dissolution by means of a fine jet of electrolyte. In this study, the effect of nozzle geometry on material removal characteristics are investigated through physical experiments performed on a Jet-ECM system under development at the university of Manchester. A total of 8 nozzles with holes encompassing converging, diverging and rounded features are studied at flow rates between 0.125 and $0.225 \mathrm{l} / \mathrm{min}$. The results show that the nozzle hole geometry has a significant effect on the machined profile produced due to variations in flow velocity, pressure, and electric current distribution with converging hole nozzles providing an increased depth of cut than the symmetrical cylindrical channel by up to 9.7\%. A 2D Star CCM+ simulation is also proposed, and numerical results developed and compared with experimental ones to investigate the feasibility of using simulation to develop future nozzle designs. The simulated results show good profile comparison to the experimental results, however, the model needs developing to improve the process repeatability for future use in nozzle design.
\end{abstract}

Keywords Jet electrochemical machining $\cdot$ Electrochemical machining $\cdot$ Nozzle design $\cdot$ Tool design $\cdot$ Simulation $\cdot$ Electrolyte jet processing

\section{Introduction}

Jet-Electrochemical machining (Jet-ECM) is a novel advancement of traditional electrochemical machining (ECM), a noncontact manufacturing process in which electrically conductive material is removed through anodic dissolution using a fine jet of electrolyte, aiming at localised machining without the use of specific tooling. Although the processes share several similarities, whereas ECM requires a tool, Jet-ECM leverages a pressurised free jet of electrolyte expelled from a small diameter nozzle (cathode) to locally remove material from a workpiece (anode). Only material exposed to the electrolyte jet is removed, therefore localised machining can be achieved through the variation of key parameters such as current and electrolyte composition, and through the controlled

Thomas Kendall

thomas.kendall@manchester.ac.uk

University of Manchester, Manchester, United Kingdom

Manchester Metropolitan University, Manchester, United Kingdom

Blueacre Technology Ltd, Dundalk, Ireland variation of machining paths [1]. Jet-ECM has been shown to be capable of achieving excellent surface finishes of down to $0.1 \mu \mathrm{m}$ Ra without altering surface material composition nor producing surface stresses and heat affected zones independent of material hardness [2].

Typically, studies are performed using nozzles with a single cylindrical, straight channel of various diameters as in the study by Natsu et al. [3]. Few studies have been performed using nozzles of more complex geometries. Kunieda et al. [4] and Kawanaka and Kunieda [5] performed studies using a flat electrolyte jet ejected from a 'letterbox' shaped nozzle. This deviation from the standard cylindrical, straight hole nozzle improved milling speed over larger areas [4] and al-lowed for mirror-like finishes of below $0.2 \mu \mathrm{m} \mathrm{Rz}$ over the larger areas [5]. The 'letterbox' nozzle alongside a straight nozzle was later studied by Zhao and Kunieda [6] with inclination of the nozzle head to the workpiece surface through a rotational axis, allowing a wider area of machining on 3D freeform surfaces. Mitchell Smith et al. [7] studied the effects of nozzle exit geometries on the energy distribution in Jet-ECM. In JetECM with a symmetrical, straight, cylindrical nozzle, the energy distribution is widely accepted as being a Gaussian distribution, with a higher energy density at the centre of 
symmetry of the electrolyte jet [7]. By varying the design of the nozzle tip geometry to vary the distance between the nozzle tip and the workpiece, Mitchell-Smith et al. [7] successfully altered the energy distribution, with different nozzle tip designs producing different machined geometries. Similar nozzles were later leveraged by Mitchell-Smith et al. [8] to produce more complex geometries than those achievable with a 'standard' cylindrical nozzle. Through leveraging these nozzle designs and introducing a rotation of the nozzle, MitchellSmith et al. [9] produced complex and bespoke geometries were achieved by varying the rotational orientation of the non-uniform nozzles to the machine path. Liu and $\mathrm{Qu}[10]$ designed nozzles with different inclined ends, on both the front and trailing edges of the nozzle. The work combined both physical and simulated experiments focusing around current distribution and electrolyte flow field, with upwards sloped nozzles producing a machined groove with a sharper edge and lower surface roughness.

Chen et al. [11] and Luo et al. [12] investigated the JetECM process using multi outlet systems. Whereas Chen et al. [11] used a mask with micro through-holes over a slit nozzle to simultaneously produce multiple channels, Luo et al. [11] used multiple tube electrodes with various lengths to produce simultaneous channels of varying geometries. In both cases the nozzles themselves were straight and cylindrical in nature.

It can be seen that through novel nozzle design, both milling speed, surface finishing and the production of specific geometry can be achieved, however, research into nozzle design has been limited, and there is an opportunity for further in-depth research into nozzle design.

In Jet-ECM, due to the nature of the process, where dissolution occurs at the location where the impinging jet hits the surface of the workpiece, the dynamic jet shape is of high importance. Although material removal is reliant on electrochemical reactions, Jet-ECM is significantly influenced by fluid dynamics [13]. Wang et al. [14] investigated the variation of the jet shape when impacting the workpiece and its influence on the edge profile produced. By controlling the direction of flow from the working area it was found a sharper edge and lower stray corrosion was seen. However, the study is focused on straight nozzles and the effect of the jet profile from the nozzle is not considered. Downstream breakup of jets, air pockets and bubbles, and expansion of electrolyte jets are all factors that can cause instability in the process and must be considered in nozzle design and flow properties such as rate and pressure. Air in the jet will act as an insulator and prohibit effective current transfer between the nozzle and workpiece.

Historically, there are several studies looking at the effect of nozzle design on fluid flows for small diameter nozzles. Several of these focus on hydro entanglement such as the work by Tafreshi et al. [15] on simulating the effect of cone geometry and the work by Begenir et al. [16] which suggested a reverse tapered nozzle increased the flow coefficient and larger spray angles. Much of the work between nozzle geometry and liquid jet properties relate to fuel injection nozzles where producing tapered nozzles can give an advantage [17]. However, in both cases pressures of the fluid flow far exceed those used in Jet-ECM. It has been shown that sharp edges and low conical angles on nozzle inlets can cause hydraulic flips [18], where boundary layer separation causes air pockets to form and can result in the formation of bubbles in the fluid flow, as well as strongly disturbing the flow steadiness inside the nozzle [19], undesirable for Jet-ECM as bubbles will act as an insulator in the electrolyte. Holes with angled inlets or rounded inlets can reduce cavitation. Longer nozzle channels can help reduce the effects of hydraulic flips as flow can reattach to the nozzle wall and redevelop a more regular flow. Expanding nozzles, with increasing diameter towards the nozzle outlet can produce constricted waterjets or detached flow [20]. Air surrounding the flow in the nozzle can reduce the friction through a nozzle due to noncontact with the side wall, however, small disturbances can change the direction of the flow, and if caused by a hydraulic flip the jet may atomise before reattachment [20], a benefit in fuel injection but not JetECM. However, these are limited examples of the effect of nozzle design, with McCarthy and Molloy [21] suggesting several more, including contraction ratios, aspect ratios, contraction angles, and surface finish of nozzles. Due to the wide range of applications and possible nozzle geometries, study into the effect of nozzle shape is vast and complex. The previous research does however raise interesting and useful points that will help to understand the flow characteristics and thus material removal characteristics in this study, which has not previously been considered in Jet-ECM research based on an extensive review of the relevant literature.

Several studies have been performed in attempting to model both the electrolyte jet shape and the material removal process. Yoneda and Kunieda [22] used finite element modelling (FEM) to calculate the energy distribution in Jet-ECM based on approximations of the jet shape. From the energy distribution, the material removal was calculated from the current density and dissolution valence. It was found that the shape obtained by the numerical calculation coincided well with the experimental result [22]. Pajak et al. [23] performed empirical modelling on the laser assisted Jet-ECM (LAJECM) and JetECM processes based on numerical modelling of energy balance equations. Results show that the numerical models provided good approximation of material removal when compared to experimental results, although further research is still required to improve the accuracy of the model. In a study using COMSOL Multiphysics software, Hackert et al. [24] developed a pseudo 3D model to simulate the current density distribution in the Jet-ECM process, using an assumed, static jet shape. Despite the lack of a dynamic flow model, simulation, and reality show good coincidence. Zhang and $\mathrm{Xu}$ [25] 
developed a 2D mathematical model for LAJECM using ANSYS software assuming a constant diameter, axisymmetric jet of fixed cross-sectional geometry. However, unlike previous studies, the workpiece profile was updated iteratively during the simulation from calculated material removal rates with the model showing good agreement between simulated and experimental results [25]. Similarly to the study by Zhang and $\mathrm{Xu}$ [25], Hackert et al. [26] built upon their previous study [24] to include a moving mesh in a transient COMSOL Multiphysics model. This moving mesh was updated to consider removal geometries during the simulation and showed improved results over their previous study [24], however, the jet shape was still assumed as constant. A similar study was later performed by HackertOschätzchen et al. [2] in COMSOL Multiphysics with remeshing due to dissolution calculated from current density distribution using an assumed jet shape.

Whereas previous studies were constructed using assumed, static jet profiles, fluid dynamics was considered in a model by Hackert-Oschätzchen et al. [27] in addition to electrodynamics and material dissolution. The depth and width of the simulations deviated from experimental results from an over estimation of current and the nonconsideration of secondary contacting and boundary resistance. However, a 2D COMSOL Multiphysics 2 stage simulation, using both fluid dynamics and boundary resistance was performed by HackertOschätzchen et al. [28] whilst continuing to use a changing mesh. Separate stages of the simulation are introduced, with the formation of the fluid jet preceding the anodic dissolution process and updated mesh geometry dependent on material removal. Results suggested material removal was overestimated in simulation when compared to experimental results. Ming et al. [29] developed a COMSOL Multiphysics simulation of the Jet-ECM process by coupling electrochemical reactions, fluid dynamics, and mass transfer as a consequence of diffusion, convection, and migration of ions in electrolyte and electrolyte-electrode interface. The distribution of Ions methods was considered to improve upon previous studies, but no comparison to experimental results was made. Whilst previous studies had used 2D axisymmetric simulations, Paul et al. [13] introduced a 3D finite volume simulation method to simulate the machining of tracks in Star CCM+. 2D models limit the simulations to machined pits, whereas the study by Paul et al. [13] considers more complex machining task such as milling and turning. Based on the computed normal electric current density on the workpiece surface, material removal was modelled according to Faraday's law using geometry deformation. The simulated cross-sectional profiles show a good qualitative and quantitative agreement with the experimental results.

Hackert-Oschätzchen et al. [30] developed a 2D axisymmetric model with pre-defined jet shape to study the oxide layer growth in Jet-ECM, noting with oxide layer growth the localised mechanism for material removal is reduced, becoming more homogenous across the layer. The results require experimental validation. Wang et al. [31] developed a 2D Multiphysics simulation studying the effects of air assistance in the Jet-ECM process, with experimental results showing a deviation of less than $11.8 \%$ to the simulated results, indicating the simulation can provide an explanation of real trials.

Outside of the work referred to here by Kunieda et al. [4], Kawanaka and Kunieda [5], Mitchell-Smith et al. [7], Mitchell-Smith et al. [8], Mitchell-Smith et al. [9] and Liu and $\mathrm{Qu}[10]$ there is limited research into nozzle geometry and flow characteristics in Jet-ECM with the possible benefits of novel nozzle design currently unrealised. For Jet-ECM to be accepted as a commercial manufacturing process, it must be stable, repeatable, reliable, and robust with an ability to accurately control the amount of material that you remove. In order to address these limitations and opportunities, the aim of this work is to study the effects of nozzle geometries on the material removal characteristics of the Jet-ECM process to improve the stability and reliability of the material removal process. Through the design of nozzles, there is an opportunity to increase the control of the material removal in Jet-ECM, and raise the prospect to produce material removal profiles that are not possible through the nozzles in previous studies. The study will analyse a total of 8 different nozzles, with converging, diverging holes and nozzles with rounded outlets considered at flow rates of $0.125,0.175$, and $0.225 \mathrm{l} / \mathrm{min}$. A series of physical experiments will be run on a Jet-ECM system under development at the University of Manchester to analyse the effect of the nozzle geometry and flow rate on the material removal profile produced. A 2D model is developed for the simulation of current density distribution incorporating fluid dynamics with a two-phase flow using Star $\mathrm{CCM}+$ (Siemens PLM Software Inc.). The results from the simulations will be used to estimate the material removal profile for each nozzle and flow rate to allow the comparison of performance between the nozzles and assess the feasibility of using simulations to develop and streamline the process of future nozzles designs as proposed by Wang et al. [31].

\section{Methodology}

\subsection{Nozzle design}

For this study, eight nozzle designs are considered representing converging and diverging channels, straight channel, and rounded outlet features. The designs cover a wide range of nozzle modifications and a range of tapers to provide an initial indication on the effect of the nozzle geometries over a range of tapers to present opportunities for future development. The geometries balance the possible range of designs with manufacturability. All the nozzles have a 
minimum channel diameter of $0.5 \mathrm{~mm}$ with the same nozzle inlet geometry. This minimum channel geometry is in line with nozzles in previous studies $[1,2,5,6]$. The nozzle geometries for the converging, diverging and rounded outlet nozzles can be seen in Fig. 1. The descriptions of the nozzles can be seen in Table 1. For this study, the nozzles and workpiece are made from 316 stainless steel and copper, respectively. Copper is selected as the workpiece material for this study because it finds applications in the photovoltaic industry, electronics, food, and aerospace industry, industries benefitting from micromachining technology. Nozzles were produced through Micro-EDM (Sarix, Switzerland) with a hole tolerance of $\pm 0.5 \mu \mathrm{m}$.

\subsection{Experimental equipment and methodology}

This investigation was performed on the Jet-ECM R500 system currently under development at the University of Manchester in collaboration with Blueacre Technology Ltd. (Ireland). The system is built upon a three-axis gantry system providing a working envelope of $400 \times 400 \times 150 \mathrm{~mm}$ with a positional accuracy of between 20 and $40 \mu$ m dependent on axis, and maximum repeatability of $12 \mu \mathrm{m}$. Electrolyte delivery is achieved through a variable flow, near pulseless micro pump capable of $1.7 \mathrm{l} / \mathrm{min}$ flow and 8 bar pressure output with filtration system and a flow control circuit for finer flow control. The machining current is provided to the nozzle and workpiece by a $1.5 \mathrm{~kW}$ programmable power supply from B and $\mathrm{K}$ Precision. A short circuit detection system is installed to provide an accurate working gap between the nozzle and workpiece. A sensor array monitors pH (Omega PHE-541210), temperature (RS Pro RTD), flow rate (Atrato 720-v00-D), and pressure (Gems Sensors 3100R0010G01B000). This data is collected, visualised, and transferred via National Instruments hardware and LabVIEW software. The path and velocity of the nozzle movement on the 3-axis system and the electrical output parameters from the power supply are programmed and controlled and logged via NI LabVIEW.
Table 1 Nozzle types

\begin{tabular}{ll}
\hline Nozzle Type & Nozzle Reference \\
\hline Straight & STR \\
Diverging $5^{\circ}$ & DIV5 \\
Converging $5^{\circ}$ & CON5 \\
Converging $10^{\circ}$ & CON10 \\
Converging $15^{\circ}$ & CON15 \\
Rounded outlet, $0.25 \mathrm{~mm}$ round & R0.25 \\
Rounded outlet, $0.5 \mathrm{~mm}$ round & $\mathrm{R} 0.5$ \\
Rounded outlet, $0.75 \mathrm{~mm}$ round & $\mathrm{R} 0.75$ \\
\hline
\end{tabular}

For the physical experiments, a series of 72 pits

were machined on the copper workpieces, three pits for each combination of flow and nozzle geometry. Nine pits were produced per nozzle with three pits produced consecutively at $0.125 \mathrm{l} / \mathrm{min}$ flow rate, followed by three at $0.175 \mathrm{l} / \mathrm{min}$ and three at $0.225 \mathrm{l} / \mathrm{min}$. Due to the nature of the nozzles, flow pressure will vary between each nozzle for a specific flow rate. For each separate machining run, a short circuit programme was run to find the $\mathrm{z}$-axis position of the top surface of the workpiece, with the nozzle being set to a working gap of $0.5 \mathrm{~mm}$ above the workpiece. The same potential difference of $50 \mathrm{~V}$ was used for machining all pits, with the current varying according to the resistance across the working gap during the $2 \mathrm{~s}$ machining time. The experimental conditions can be seen in Table 2 .

Following the machining trials, the samples were cleaned with lemon juice concentrate (weak citric acid) to remove the discolouration from the surface of the material as well as to remove any remaining debris and residual nitrate salts on the surface. Each machined pit was analysed under a Keyence VHX-5000 (Keyence, Japan) to calculate the machined profile of the pits, with a central cross section taken to measure the machined depth profile of each pit to compare to the simulated results.
Fig. 1. a Nozzle geometry for $5^{\circ}$ converging nozzle, $\mathrm{b} 5^{\circ}$ diverging nozzle and $\mathbf{c} 0.5 \mathrm{~mm}$ rounded outlet nozzle
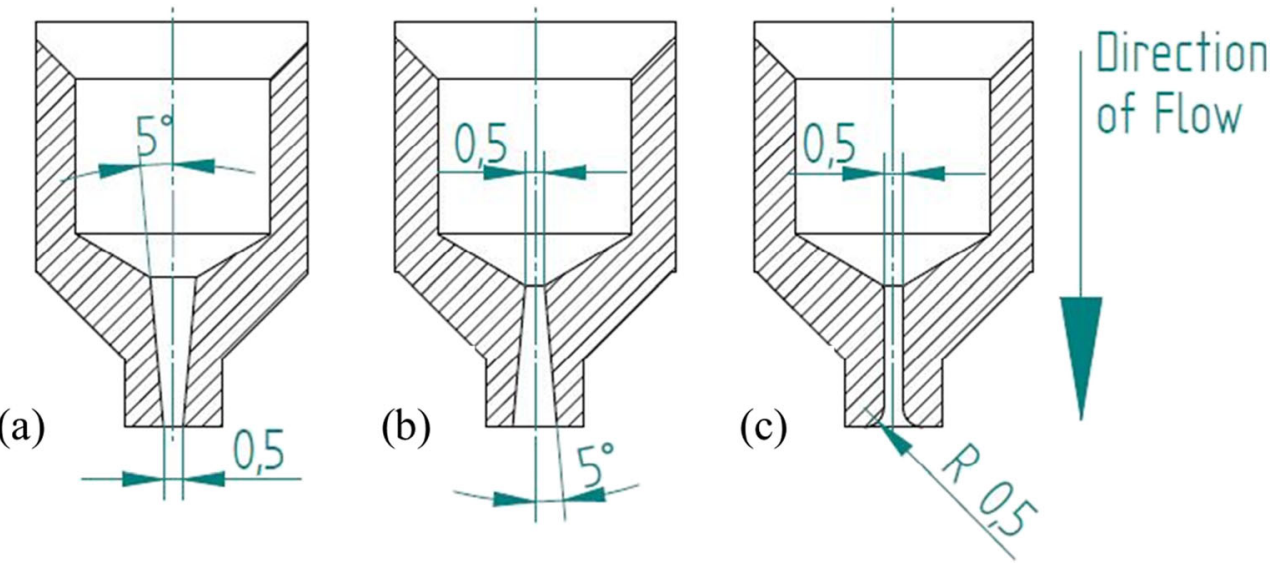
Table 2 Experimental conditions

\begin{tabular}{ll}
\hline Electrolyte & Sodium Nitrate aqueous solution \\
\hline Electrolyte Electrical Conductivity & $165 \mathrm{mS} / \mathrm{cm}$ at $20^{\circ} \mathrm{C}$ \\
Flow rate & $0.125-0.2251 / \mathrm{min}$ \\
Working gap & $0.5 \mathrm{~mm}$ \\
Gap potential difference & $50 \mathrm{~V}$ \\
Machining time per pit & $\underline{2 \mathrm{~s}}$ \\
\hline
\end{tabular}

$165 \mathrm{mS} / \mathrm{cm}$ at $20^{\circ} \mathrm{C}$

\subsection{Jet-ECM modelling}

Numerical simulations were performed using Star CCM+ simulation a 2D Volume of fluid (VOF) model was developed for each of the 8 nozzle geometries. A decision to not use an axisymmetric model, as per previous literature, was taken as it cannot be assumed that when using an expanding nozzle or nozzle with rounded outlet, the flow will be axisymmetric to the centre of the nozzle. The 2D model geometry for the straight nozzle can be seen in Fig. 2. The models feature a working gap of $0.5 \mathrm{~mm}$ between the nozzle and the workpiece surface in all cases.

As seen in Fig. 2b, boundary 1 represents the fluid inlet, boundary 2 the nozzle wall, boundary 3 the flow outlet, and boundary 4 the workpiece top surface. The geometry was meshed using a surface remesher with trimmed cell mesh with a base size and maximum cell size of $0.01 \mathrm{~mm}$. For the straight nozzle, this resulted in a mesh with 158,650 quadrilateral cells and 315,493 faces in a structured grid.

\subsubsection{Fluid dynamics}

The two-phase flow of electrolyte and air is described using the Reynolds averaged Navier-Stokes equation with the VOF

(a)

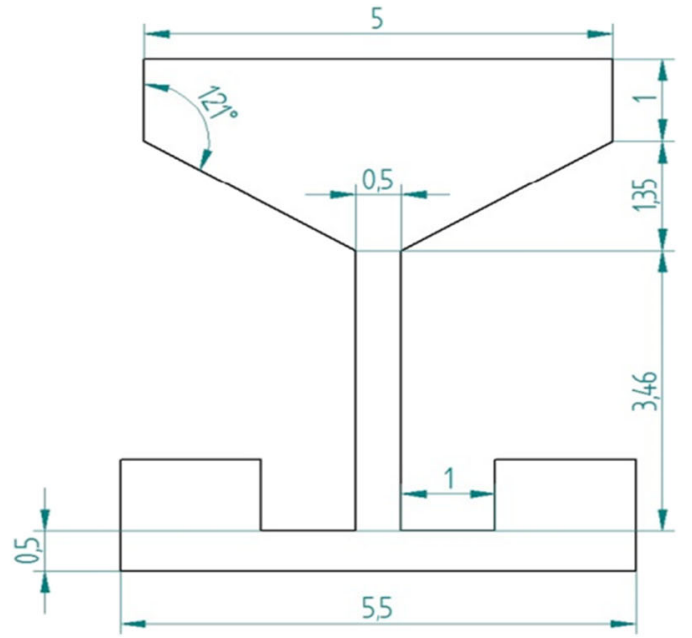

model. At the lowest flow rate, the Reynolds number Re 4250 and is therefore, in the turbulent region, with the flow condition set accordingly and the K-epsilon turbulence equation used. The electrolyte used for this study is sodium nitrate aqueous solution with a conductivity of $165 \mathrm{mS} / \mathrm{cm}$ at $20{ }^{\circ} \mathrm{C}$ considered to be incompressible. The material properties of the electrolyte and air phases are shown in Table 3.

Considered boundary conditions for the fluid mechanics can be seen in Table 4 . The velocity of the flow normal to the inlet boundary was set as a constant for each flow rate. Considering a nozzle inlet diameter of $5 \mathrm{~mm}$, and assuming flow rates of $0.125,0.175$ and $0.225 \mathrm{l} / \mathrm{min}$ the corresponding inlet velocities were $1.06,1.49$, and $1.91 \mathrm{~m} / \mathrm{s}$, respectively. At $\mathrm{t}=0 \mathrm{~s}$ in the simulation, the working area was defined as being $100 \%$ air, with the flow into the inlet being assumed to be $100 \%$ electrolyte.

\subsubsection{Electrodynamics}

In this simulation, the electrodynamics relates to the current distribution through the electrolyte between the anode and cathode with the primary function of estimating the current density distribution on the workpiece. The modelling of the current distribution relies heavily on the conductivity through the fluid domain, defined by the volume weighted mixture of air and electrolyte. However, to allow stability of the simulation, the air is assumed to have no conductivity. Although air does have a small conductivity value, it is considered to be negligible and assumed to be zero.

In the Star CCM+ model the electrodynamic potential and electromagnetics models were included and assumes constant voltage for this study. Although there is electrode overpotential between the 316 stainless steel cathode and the copper anode, as well as resistance overpotential in the oxide layer, the values can be neglected as to keep constant across all studies. The potential difference across the electrodes is $50 \mathrm{~V}$

(b)

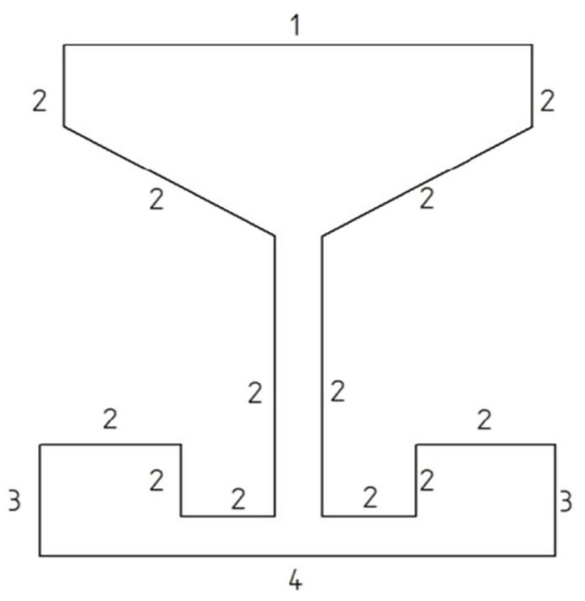

Fig. 2. a Model dimensions in $\mathrm{mm}$ and boundary definitions, b for straight nozzle 
Table 3 Properties of Sodium Nitrate Electrolyte at $20^{\circ} \mathrm{C}[[34,35]]$ and air at 1 bar and $20^{\circ} \mathrm{C}[36]$

\begin{tabular}{lll}
\hline Material Electrolyte & $\begin{array}{l}\text { Property } \\
\text { Surface Tension } \\
\text { Electrical Conductivity }\end{array}$ & Value \\
& $79.5 \mathrm{mN} / \mathrm{m} 165 \mathrm{mS} / \mathrm{cm}$ \\
\hline \multirow{4}{*}{ Air } & Density & $1221.51 \mathrm{~kg} / \mathrm{m}^{3}$ \\
& Dynamic Viscosity & $1.607 \mathrm{mPa} \mathrm{s}$ \\
& Density & $1.1885 \mathrm{~kg} / \mathrm{m}^{3}$ \\
& $\underline{\text { Dynamic Viscosity }}$ & $\underline{18.205} \underline{\mu \mathrm{Pa} \mathrm{s}}$ \\
\hline
\end{tabular}

for all the models, the voltage at the anode surface being $50 \mathrm{~V}$, and that on the cathode $0 \mathrm{~V}$. The electrical resistance of both materials are considered to be $7.410^{-7} \Omega \mathrm{m}$ and $1.6810^{-8} \Omega \mathrm{m}$ for 316 stainless steel and copper, respectively [32]. The boundary conditions can be seen in Table 5 .

\subsubsection{Solver methods}

For all 24 models ( 8 nozzles at 3 flow rates), the implicit unsteady solver was run with $0.001 \mathrm{~s}$ time steps and $1^{\text {st }}$ order temporal discretisation. The simulation was run for a total of $1 \mathrm{~s}$ of physical time to allow for the flow and the current distribution to become steady. The process was thought to be stable when continuity, $\mathrm{x}$-momentum, $\mathrm{y}$-momentum, and electric potential residuals were in the magnitude of $10^{-6}$.

After the simulation finished, the velocity magnitude was recorded across the nozzle outlet at $0.01 \mathrm{~mm}$ intervals to compare the effect of nozzle geometries on flow velocities. The current density magnitude was measured across the workpiece surface up to $1.25 \mathrm{~mm}$ either side of the line of symmetry at $0.005 \mathrm{~mm}$ intervals as seen in Fig. 3 .

\subsubsection{Material removal}

The theoretical removal rates for the simulations are based upon Faraday's law of electrolysis [33]:

$m=\frac{A I t}{z F}$

Table 4 Boundary conditions of fluid dynamics, labelling according to Fig. 2b

\begin{tabular}{lll}
\hline Boundary & Description & Condition \\
\hline 1 & Flow inlet & Normal velocity inlet \\
2 & Nozzle wall & No-slip wall \\
3 & Open outlet & Pressure Outlet, atmospheric pressure. \\
4 & Workpiece surface & No-slip wall \\
\hline
\end{tabular}

Table 5 Electrodynamic Boundary Conditions, labelling according to Fig. 2b

\begin{tabular}{lll}
\hline Boundary & Description & Condition \\
\hline 1 & Flow Inlet & Insulator \\
2 & Nozzle Wall & $\mathrm{V}=0 \mathrm{~V}, \rho=7.4 \times 10^{-7} \Omega \mathrm{m}$ \\
3 & Open Outlet & Insulator \\
4 & Workpiece Surface & $\mathrm{V}=50 \mathrm{~V}, \rho=1.68 \times 10^{-8} \Omega \mathrm{m}$ \\
\hline
\end{tabular}

where $\mathrm{m}$ is the mass of material removed in grams ( $\mathrm{g}$ ), $\mathrm{A}$ is the atomic weight, $\mathrm{z}$ is the valency, $\mathrm{t}$ is the time the current is applied in seconds (s) and I is the current in Amps (A). From the simulation, the current density magnitude was measured across the workpiece, from $\mathrm{x}=-1.25 \mathrm{~mm}$ to $\mathrm{x}=1.25 \mathrm{~mm}$ from the centre of symmetry at $0.005 \mathrm{~mm}$ intervals, i.e.,

$x_{n+1}-x_{n}=0.005 \mathrm{~mm}$

where $\mathrm{X}_{n}$ and $\mathrm{X}_{n+1}$ are 2 consecutive measurement points. As the current density is only measured at specific points in the $\mathrm{x}$-direction, and is itself dependent on the area, the following calculations require a coordinate between measured points representing a central coordinate between two $\mathrm{x}$ points, in this case $\mathrm{x}_{\text {avg }}$ :

$x_{\text {avg }}=\frac{x_{n+1}+x_{n}}{2}$

where $\mathrm{x}_{n}$ and $\mathrm{x}_{n+1}$ are two consecutive measured coordinates. Therefore, the area between 2 measured coordinates, $\mathrm{A}\left(\mathrm{x}_{\text {avg }}\right)$, rotated $180^{\circ}$ to represent half a symmetrical 3D model is:

$A\left(x_{\text {avg }}\right)=\frac{1}{2}\left(\pi x_{n+1}^{2}-\pi x_{n}^{2}\right)$

and the average current density magnitude between two $\mathrm{x}$ coordinates, $\mathrm{J}\left(\mathrm{x}_{\text {avg }}\right)$, is:

$J\left(x_{\text {avg }}\right)=\frac{J\left(x_{n}\right)+J\left(x_{n+1}\right)}{2}$

where $J(x)$ is the measured current density magnitude in $\mathrm{A} / \mathrm{mm}^{2}$. The specific current in Amps (A) at that point, $\mathrm{I}\left(\mathrm{x}_{\text {avg }}\right)$, is:

$I\left(x_{\text {avg }}\right)=A\left(x_{\text {avg }}\right) \times J\left(x_{\text {avg }}\right)$

The material removed rate in grams $(\mathrm{g}), \mathrm{m}\left(\mathrm{x}_{\mathrm{avg}}\right)$ based on equation 1 , is:

$m\left(x_{\text {avg }}\right)=\frac{A I\left(x_{\text {avg }}\right) t}{z F}$ 


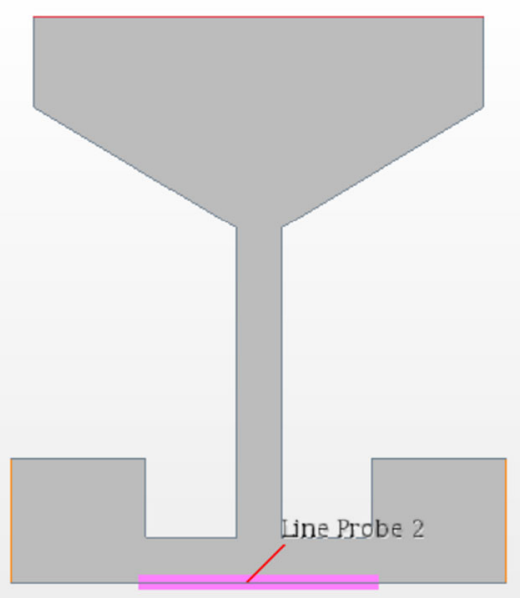

Fig. 3. Location of current density measurement

where $\mathrm{A}$ is the atomic weight of copper, $63.546 \mathrm{u}, \mathrm{z}$ is the valency of copper, in this case, a valency of 2 [33], $t$ is the machining time, $2 \mathrm{~s}$, and $\mathrm{F}$ is the Faraday constant, 96,485.33 $\mathrm{C} \mathrm{mol}^{-1}$. From this material removal calculation, and using the density of copper, $\rho=8.9610^{-3} \mathrm{~g} / \mathrm{mm}^{3}$, the volumetric removal, $\mathrm{V}\left(\mathrm{x}_{\text {avg }}\right)$ in $\mathrm{mm}^{3}$ is:

$V\left(x_{a v g}\right)=\frac{m\left(x_{a v g}\right)}{\rho}$

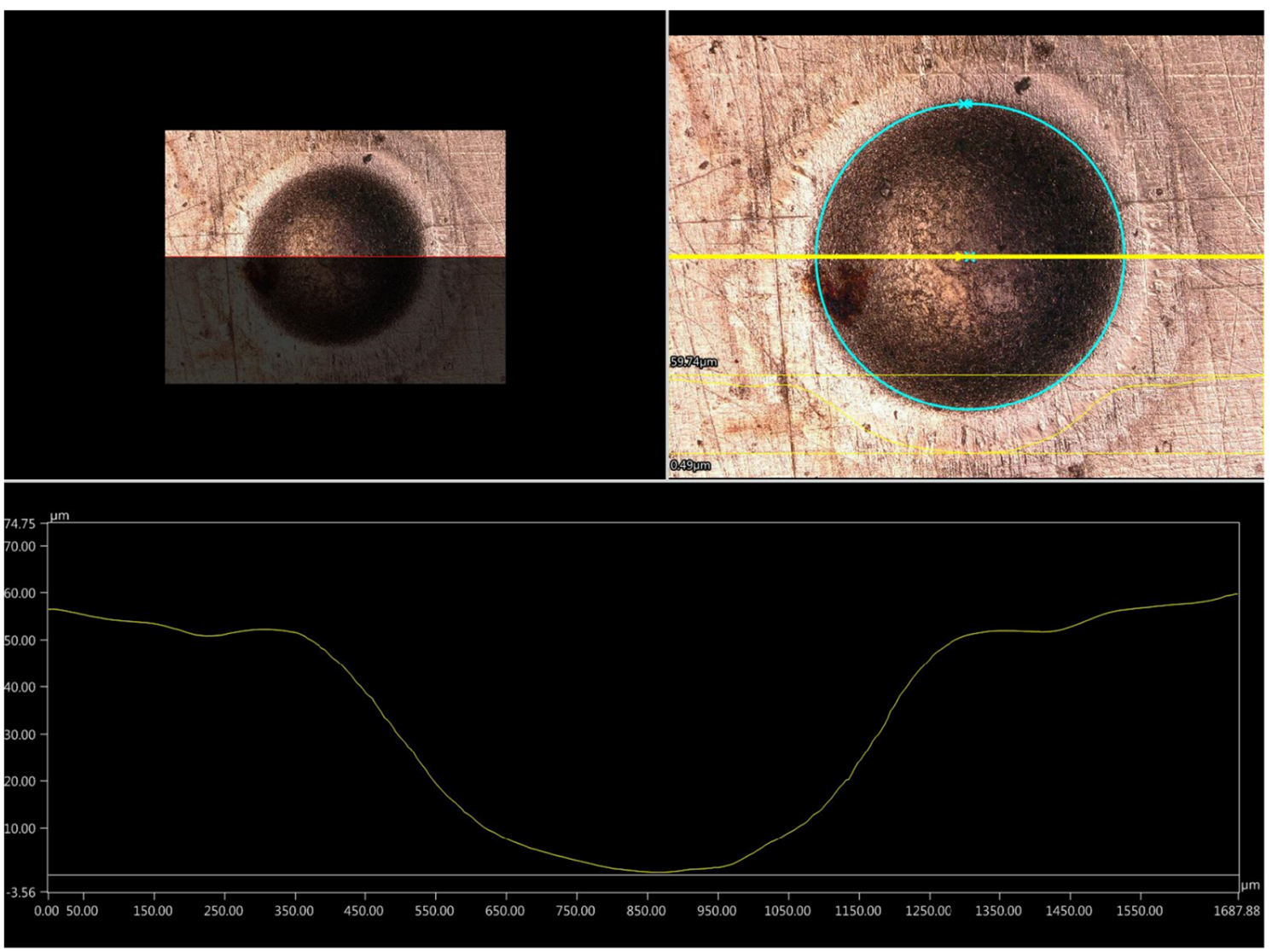

Fig. 4. Example of experimental depth measurement 

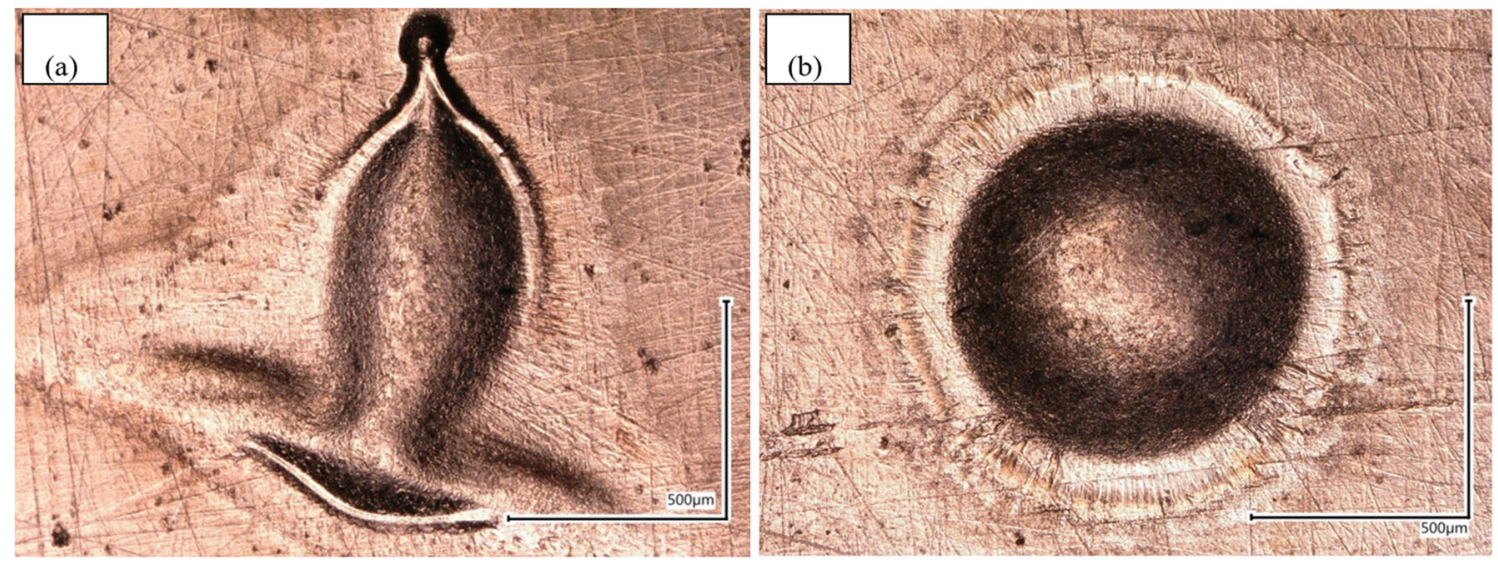

Fig. 5. a Image of machined profile for the diverging nozzle at $0.175 \mathrm{l} / \mathrm{min}$ flow rate, $\mathrm{x} 200$ magnification. b Machined pit using CON10 nozzle, $0.175 \mathrm{l} /$ min flow rate, $\mathrm{x} 200$ magnification

in the flow or movement of the nozzle head in repositioning. For the trials of the remaining nozzles, the machined profiles are a hemispherical pit as seen in Fig. 5b.

Material removal is directly proportional to the distribution of the current on the workpiece surface, i.e., the areas of machining that are deepest are linked to the highest current density, and the shallowest areas are the areas of lowest current
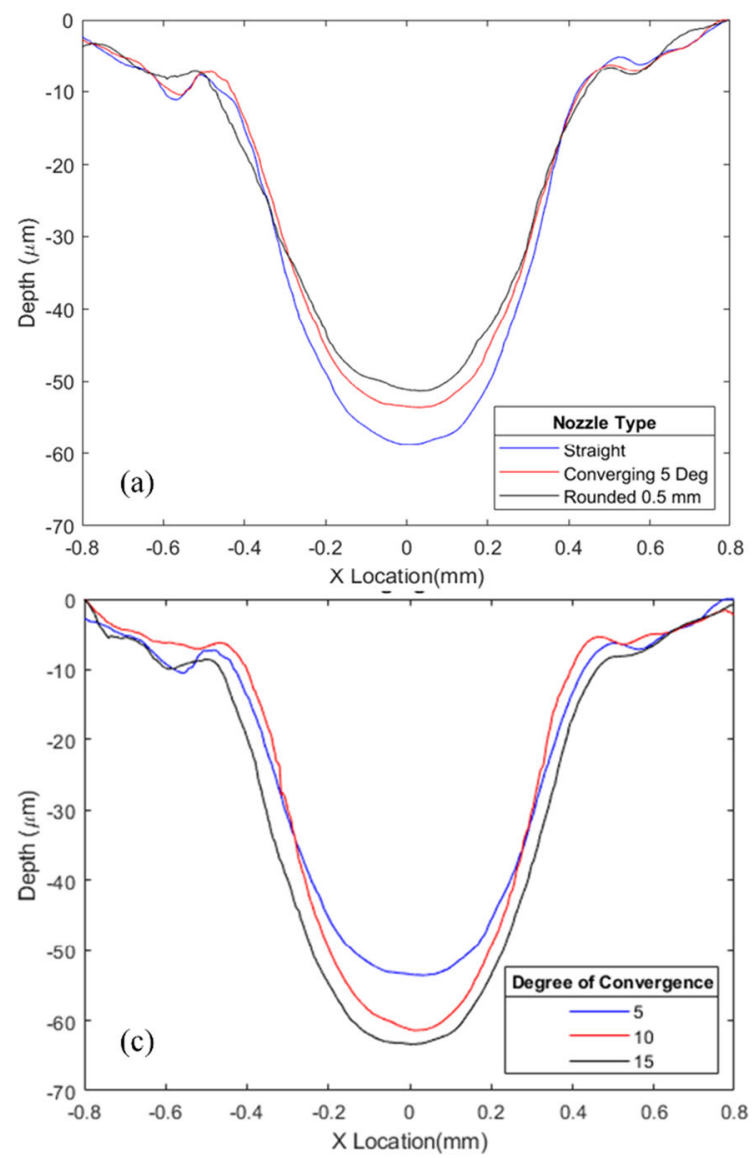

Fig. 6. a Experimental depth profile for various nozzles at $0.1751 / \mathrm{min}$ flow rate. $\mathbf{b}$ Experimental depth profiles for the rounded outlet nozzles at $0.175 \mathrm{l} / \mathrm{min}$ flow rate. c Experimental depth profiles for the converging density. Current density distribution is Gaussian in nature and would mirror the material removal profiles. The transfer of current between the workpiece and nozzle occurs through the electrolyte jet, and therefore, the jet shape and flow profile across the workpiece influence the current density distribution.
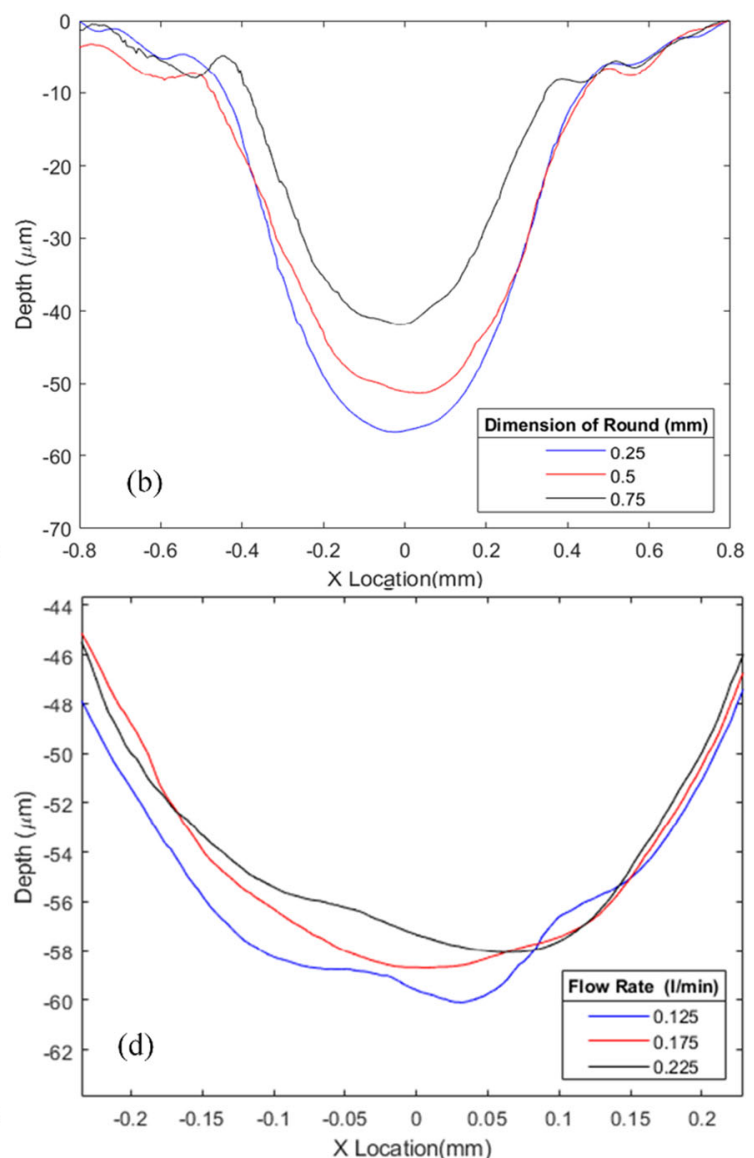

nozzles at $0.1751 / \mathrm{min}$ flow rate. d Experimental depth profiles for the straight nozzle at varying flow rates 
When comparing the effect of the varying nozzle designs, nozzle CON15 produced the deepest profile $(63.37 \mu \mathrm{m})$, followed by CON10 $(61.37 \mu \mathrm{m})$, the straight nozzle (STR) $(58.7 \mu \mathrm{m})$, CON5 $(53.57 \mu \mathrm{m})$, and the rounded outlet nozzles (R0.25, R0.5 and R0.75, respectively) (Figs. $6 \mathrm{a}, \mathrm{b}, \mathrm{c}$ ).

It is expected that the rounded nozzles would produce a lesser machined depth than the straight and converging nozzles due to the larger distance between the point of separation of the flow from the nozzle and the workpiece surface, a gap which should increase with a larger round feature. This larger distance increases the gap resistance, and reduces the current passed through the electrolyte and subsequent material removal, as in Fig. 6b. This is observed in a decrease of up to 9.3\%, $20.2 \%$, and $31.6 \%$ for the R0.25, R0.5, and R0.75 nozzles, respectively when compared to the depth of cut achieved by the straight nozzle at the same machining parameters. A larger rounded feature could also lead to jet expansion at the nozzle outlet, which would be visualised with a wider machined channel, however as seen in Fig. 6b, the width of the machined pit shows no trend with increasing round size, with the largest round producing the narrowest pit with no difference between the remaining two rounded nozzles. This indicates a similar jet profile for nozzles R0.25, R0.5, and R0.75 with the narrowest channel with the largest rounding attributed to a lower current density from increased resistance, and with the current profile reducing in the radial direction, the lower current limit for material removal occurs farther towards the centre of the jet.

The effect of nozzle convergence angle is presented in Fig. $6 c$. The depth of profile is increased with a higher degree of convergence, with a difference of $10 \mu \mathrm{m}$ between the nozzles CON5 and CON15 at $0.175 \mathrm{l} / \mathrm{min}$ flow rate. Both the CON10 and CON15 nozzles produced a greater depth than that produced by the straight nozzle with the CON5 nozzle producing a lesser depth than the straight nozzle, with these trends mirrored across all flow rates. When compared to the straight nozzle, the CON10 nozzle produced a percentage increase of depth between $4.5 \%$ and $9.7 \%$ depending on flow rate, the CON15 nozzle produced a percentage increase in depth of between $7.9 \%$ and $9.3 \%$ depending on flow rate, whilst the CON5 nozzle produced a percentage decrease in depth of between $5.1 \%$ and $8.7 \%$. This indicates there is an effect from the degree of convergence, however, there is a degree of convergence at which the benefits of converging nozzles begin. There is a small variation in the widths of the pits produced, however, this variation shows no correlation to the degree of convergence. This trend in Fig. $6 \mathrm{c}$ is likely due to the converging nozzles sharing the same nozzle outlet diameter which dominates the material removal profile due to the shortest path of resistance to the workpiece. From the measured flow pressure profiles (Fig. 7a) the width of the pit increases with increasing flow pressure suggesting pit width is related to flow pressure, however, minor fluctuations in the radial flow,
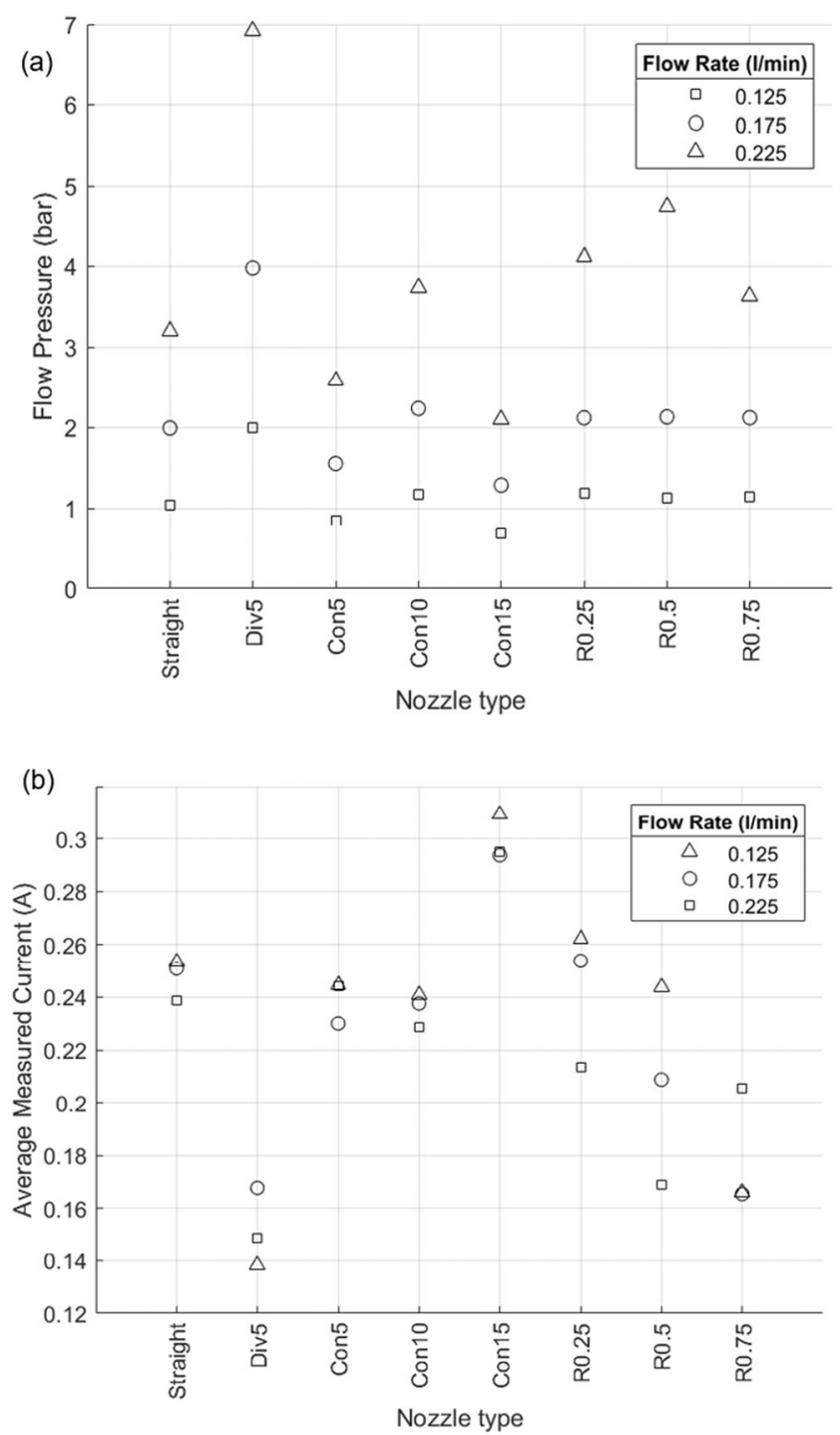

Fig. 7. a Measured flow pressure for all nozzles and flow rates, b Average applied current for all flow rates

debris removal, and workpiece profile could lead to variations in the machined profile width.

The effect of flow rate on the machined profile is presented in Fig. 6d. There is a trend of decreased depth with increasing flow rate, but with a variation of only $3 \mu \mathrm{m}$ between the shallowest and deepest profiles, whilst the width of the profiles shows no significant difference with varying flow rates. Over the range of flow rates for these experiments, there is not enough variation in the jet produced to produce significant differences, with no atomisation or laminar to turbulent transitions occurring within the working gap, aside from that seen in the diverging nozzle.

As the current is the dominant parameter for material removal in the Jet-ECM process, it is expected that the applied current will be proportional to the machined depth. In general, the depth profiles match that of the average recorded current during processing (Fig. 7b). However, there are anomalies to 
this trend. Although the CON10 nozzle shows a lower average current than that of the straight and CON5 nozzle, the machined depth is higher. It can be seen in Fig. $7 b$ that the measured current shows a much higher variation over the three flow rates on the rounded outlet nozzles in comparison to the straight and converging nozzles, indicating that the rounded outlet nozzles are more sensitive to flow rate. The sampling rate for current measurements was $10 \mathrm{~Hz}$ for this study, and therefore, is only representative of the machining currents, and may not represent all fluctuations in the applied current. However, if used as an indication of the process, it is thought that with constant parameters, and flow rates, that the velocity profile and jet pressure may also be a significant factor on the machined depth.

The standard deviations calculated from the 3 trials

for each nozzle and flow configuration are presented in Table 6. Due to the erratic nature of the diverging nozzle as previously described, the standard deviations are not calculated for the trials with the diverging nozzle. In general, the standard deviation shows good repeatability for both the depth measurements, and the measured applied machining current. The standard deviations are higher in the trials with $0.225 \mathrm{l} / \mathrm{min}$ flow rates, indicating higher variation in the process at higher flow rates. The deviation in depth from the $0.75 \mathrm{~mm}$ rounded outlet nozzle (R0.75) at $0.225 \mathrm{l} / \mathrm{min}$ is very high when compared to the other trials, indicating a less controlled, repeatable process with the larger round, possibly due to the higher resistance across the gap being more susceptible to variations in the machining process.

From the theoretical head loss values in Table 7, it would be expected that the pressure required to maintain a constant flow rate through the nozzles would be higher for the straight nozzles than the converging nozzles, and for the converging nozzles would increase with increasing degree of convergence. However, from the measured flow pressure (Fig. 7a),
Table 7 Theoretical head loss (m) through nozzles, calculated from Cameron Hydraulic Data [37]

\begin{tabular}{lllll}
\hline Study & Nozzle Reference & \multicolumn{3}{l}{ Flow Rate $(1 / \mathrm{min})$} \\
\cline { 3 - 5 } & & 0.125 & 0.175 & 0.225 \\
\hline 1 & STR & 4.294 & 8.183 & 13.269 \\
2 & DIV5 & 3.518 & 6.895 & 11.397 \\
3 & CON5 & 0.028 & 0.805 & 1.330 \\
4 & CON10 & 0.059 & 1.605 & 2.653 \\
5 & CON15 & 0.075 & 2.377 & 3.929 \\
6 & R0.25 & 4.162 & 7.941 & 12.888 \\
7 & R0.5 & 4.030 & 7.699 & 12.507 \\
$\underline{8}$ & R0.75 & $\underline{3.898}$ & $\underline{7.457}$ & $\underline{12.126}$ \\
\hline
\end{tabular}

although the CON5 and CON15 nozzles show a lower pressure than the straight nozzle, the CON10 nozzle shows a higher pressure. The head loss values for this study are theoretical and are therefore, estimates, and each nozzle needs to be quantified experimentally, and should be included in future works to better analyse the pressure differences across the nozzles. It is worth noting that the pressure profiles for the rounded outlet nozzles are similar for the 0.125 and $0.175 \mathrm{l} /$ min flow rates, but more varied at the higher $0.225 \mathrm{l} / \mathrm{min}$ flow rate, where the exit conditions may be more turbulent.

\subsection{Simulated results and comparison}

\subsubsection{Fluid dynamics}

The volume fraction of electrolyte was visually recorded for each simulation trial to analyse the simulated flow shape. Figure 8 shows the flow of electrolyte for the simulation using the straight nozzle for a $0.125 \mathrm{l} / \mathrm{min}$ flow rate after a simulated time of $1 \mathrm{~s}$. The area in red represents the flow of

Table 6 Standard Deviation of Depth and Machining Current from experimental trials (2 repeats)

\begin{tabular}{llllll}
\hline $\begin{array}{l}\text { Nozzle type/flow } \\
\text { rate }(1 / \mathrm{min})\end{array}$ & $\begin{array}{l}\text { Standard } \\
\text { deviation: depth }(\mu \mathrm{m})\end{array}$ & $\begin{array}{l}\text { Standard deviation: } \\
\text { current }(\mathrm{A})-\end{array}$ & $\begin{array}{l}\text { Nozzle type/flow } \\
\text { rate }(1 / \mathrm{min})\end{array}$ & $\begin{array}{l}\text { Standard deviation: } \\
\text { depth }(\mu \mathrm{m})\end{array}$ & $\begin{array}{l}\text { Standard deviation: } \\
\text { current }(\mathrm{A})\end{array}$ \\
\hline Straight $/ 0.125$ & 0.5254 & 0.0019 & $\mathrm{CON} 15 / 0.225$ & 0.5316 & 0.0050 \\
Straight $/ 0.175$ & 1.8898 & 0.0028 & $\mathrm{R} 0.25 / 0.125$ & 0.6995 & 0.0017 \\
Straight / 0.225 & 2.5408 & 0.0027 & $\mathrm{R} 0.25 / 0.175$ & 0.4535 & 0.0096 \\
CON5 / 0.125 & 1.4018 & 0.0035 & $\mathrm{R} 0.25 / 0.225$ & 1.0359 & 0.006 \\
CON5 / 0.175 & 0.6986 & 0.0063 & $\mathrm{R} 0.5 / 0.125$ & 0.8773 & 0.0054 \\
CON5 / 0.225 & 1.8617 & 0.0241 & $\mathrm{R} 0.5 / 0.175$ & 0.5511 & 0.0120 \\
CON10 / 0.125 & 0.9853 & 0.0005 & $\mathrm{R} 0.5 / 0.225$ & 1.0826 & 0.0005 \\
CON10 / 0.175 & 2.8041 & 0.0054 & $\mathrm{R} 0.75 / 0.125$ & 1.3431 & 0.0012 \\
CON10 / 0.225 & 1.8231 & 0.0177 & $\mathrm{R} 0.75 / 0.175$ & 0.6021 & 0.0081 \\
CON15 / 0.125 & 1.1474 & 0.0016 & $\mathrm{R} 0.75 / 0.225$ & 19.3472 & 0.0036 \\
CON15 / 0.175 & 1.5920 & 0.0065 & & & \\
\hline
\end{tabular}




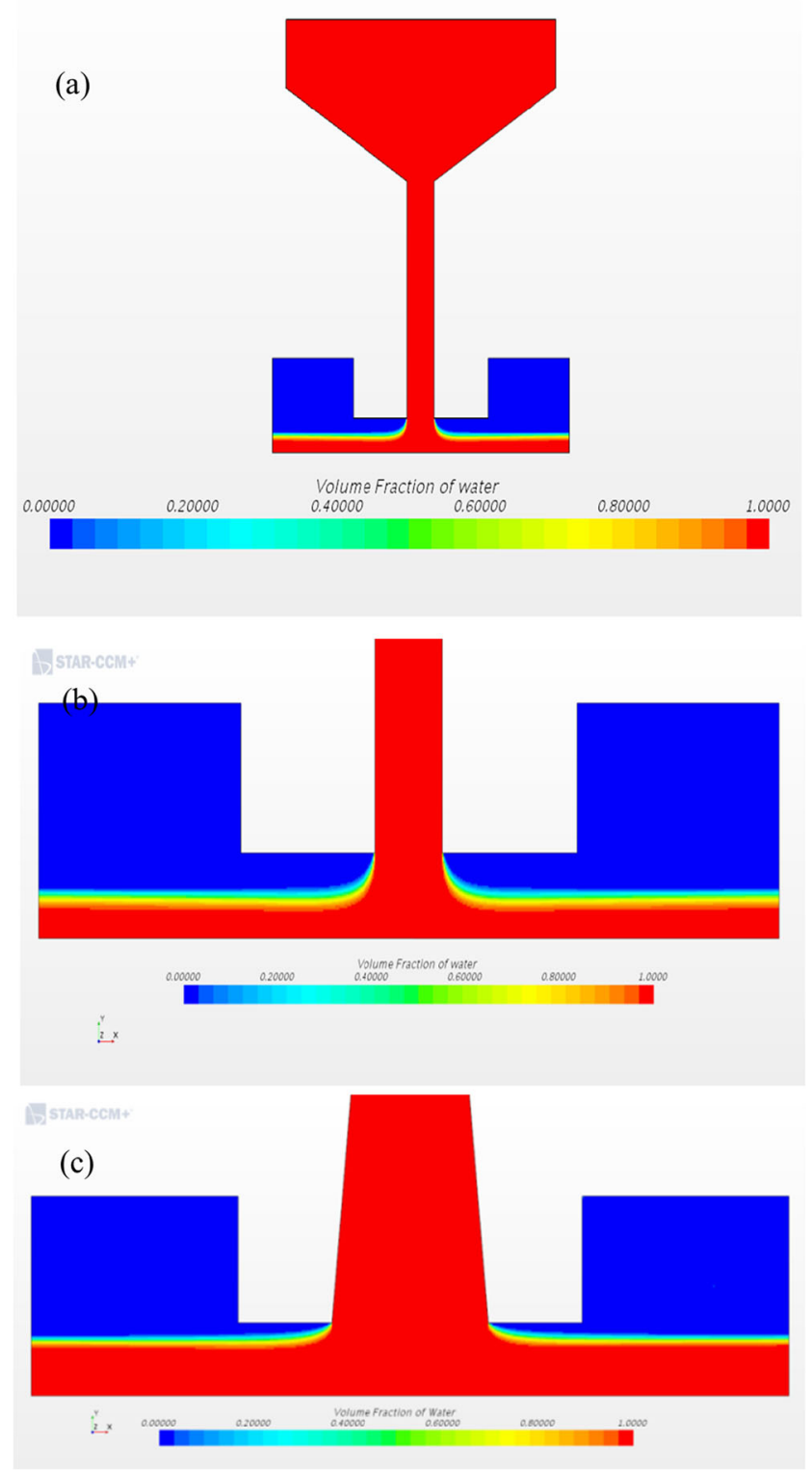

Fig. 8. a Volume Fraction of electrolyte, $\mathrm{t}=1 \mathrm{~s}$, STR nozzle, $0.125 \mathrm{l} / \mathrm{min}$ flow rate, b Volume Fraction of electrolyte, $t=1$ s, STR nozzle, 0.125 1/ min flow rate, focused on nozzle outlet, $\mathbf{c}$ Volume Fraction of Electrolyte for DIV5 nozzle, $\mathrm{t}=1 \mathrm{~s}, 0.175 \mathrm{l} / \mathrm{min}$ flow rate, focused on nozzle outlet

electrolyte, whilst that in blue represents the free air. It can be seen from Fig. 8 that the flow shape is symmetrical, with a uniform flow towards the outlet, with no hydraulic jump forming before the outlet.

This trend is apparent throughout the converging nozzles (Fig. 9), with very little visual difference between the various convergences and the straight nozzle for all flow rates. There appears to be no further convergence in the jet flow after exiting the nozzle, as a straight flow develops and expands outwards when contact has been made with the workpiece, as seen in the straight nozzle. However, the diverging nozzle and the rounded nozzles showed different behaviours. The diverging nozzle, as seen in Fig. 8c shows the flow expanding throughout the nozzle passage, remaining connected to the nozzle wall instead of separating from the nozzle at the point of smallest diameter and producing a constricted jet. Due to the expansion, the flow will be decelerating through the nozzle passage, exiting the nozzle at a lower velocity than if the flow had separated. This lower velocity is indicated by the deeper radial flow over the workpiece than that of the straight and converging nozzles as seen by the height of the red section along the workpiece in Figs. 8-10. It is believed higher radial velocities remove debris from the working area at a higher rate, as well as reducing the contact area of the impinging jet on the workpiece surface.

Whereas the straight, converging and diverging nozzles showed symmetrical flow behaviour, the nozzles with rounded outlets showed different behaviour. It can be seen in Fig. 10 that the flow of electrolyte separates from the nozzle wall at different points, possibly caused by an asymmetrical mesh. Due to the mesh, flow calculations and friction effects are not identical on each nozzle wall, and on one side of the nozzle wall the flow bends away from the centre. Although this could be avoided using a symmetric mesh, the asymmetric mesh better represents any manufacturing defects and imperfections which would lead to these same flow separation effects, and justifies the use of said mesh. This characteristic is increased with a larger round on the nozzle outlet and by increased flow rate. An asymmetrical flow could impact the machined shape, due to an irregular impact of the jet on the surface, variable working gaps and irregular debris removal from the jet shape.

Although the nozzles all have a minimum diameter of 0.5 $\mathrm{mm}$, the velocity profiles through the nozzles are not constant due to different head loss characteristics in the channel and subsequently different pressure profiles. As it can be seen in Table 7, the theoretical head losses (h) varies greatly depending on geometry, but is dominated by the reduction in nozzle diameter after entry, as seen in those nozzles where the diameter drops from 5 to $0.5 \mathrm{~mm}$ through the channel (See Fig. 1).

These variations in flow are evident when comparing the flow profiles at the nozzle outlets, as shown in Fig. 11, presenting the velocity magnitude of the flow across the nozzle outlet. Figure 11a shows the velocity magnitude across the nozzle exits for the converging nozzles compared to the straight nozzle. It can be seen that the profile is representative of turbulent flow, with a flatter profile at the centre of flow and the sharp decrease in velocity at the wall boundary. Although this is expected, the velocity profiles of the converging nozzles show an inverse curve to that of either laminar or turbulent flow, with the velocity lower at the centre of the flow. Although velocity magnitude takes in to account the velocity magnitude in both the $\mathrm{x}$ and $\mathrm{y}$ directions, the same flow profile is seen when only monitoring the velocity in the y-direction. The effect of the nozzle convergence on the flow velocity profile shows a greater velocity magnitude nearer the nozzle wall due to the increased horizontal velocity from increased 
Fig. 9. a. Volume Fraction of Electrolyte for CON5, b CON10, and $\mathbf{c}$ CON15 nozzles at $\mathrm{t}=1 \mathrm{~s}$, $0.175 \mathrm{l} / \mathrm{min}$ flow rate

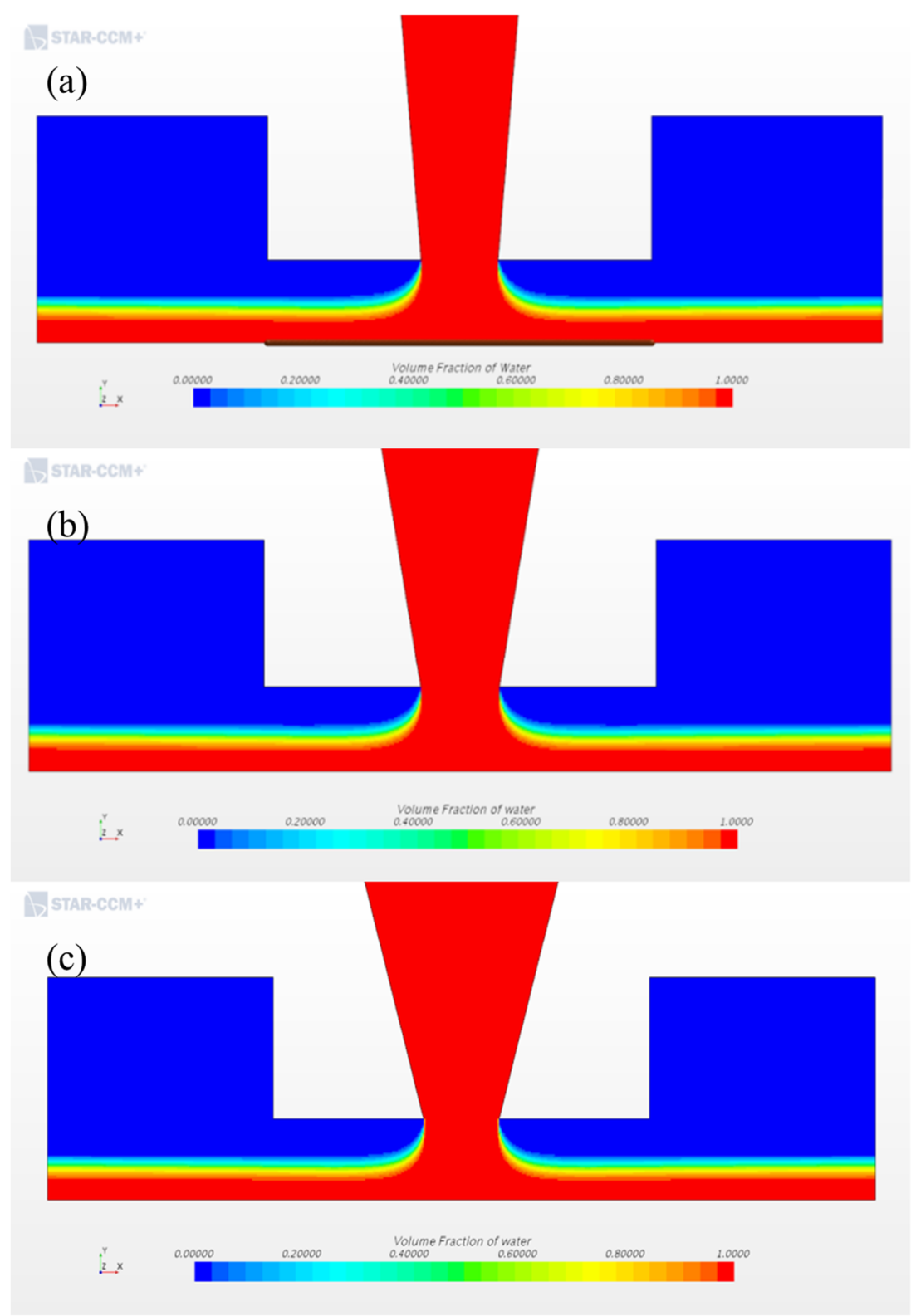

convergence angles. The velocity magnitude is however, greater at the centre of flow with a smaller convergence angle. This increased flow velocity could improve the removal of debris at the centre of the machined profile.

When comparing the straight and diverging nozzles (Fig. $11 \mathrm{~b})$, the velocity profile of the diverging nozzle shows a profile more similar to that of laminar flow, with a gradual increase in velocity from the wall boundary when compared to the straight nozzle. Due to the increased outlet area in the diverging nozzle, and constant flow rate, the values of velocity magnitude are lower in the diverging nozzle, however, in the case where the flow may separate from the nozzle wall, this velocity profile would differ greatly. Figure 11c shows the velocity magnitude comparison for the nozzles with rounded outlets compared to the straight nozzle profile. Towards the centre of the flow, the rounded outlet nozzles show a similar flow profile to the straight nozzle, however, the magnitude at the centre of the nozzle decreases with an increased size of the round. With the increased outlet area from the inclusion of the round the flow profile is wider with the rounded outlet nozzles.

The spikes in velocity that can be seen are dominated

by velocity in the direction parallel to the nozzle outlet, i.e., perpendicular to the symmetry of the nozzle. When analysing the velocity magnitude in the direction parallel to the nozzle (y-direction) then the velocity profile is similar to that of the straight nozzle with the velocity decreasing to zero at the 


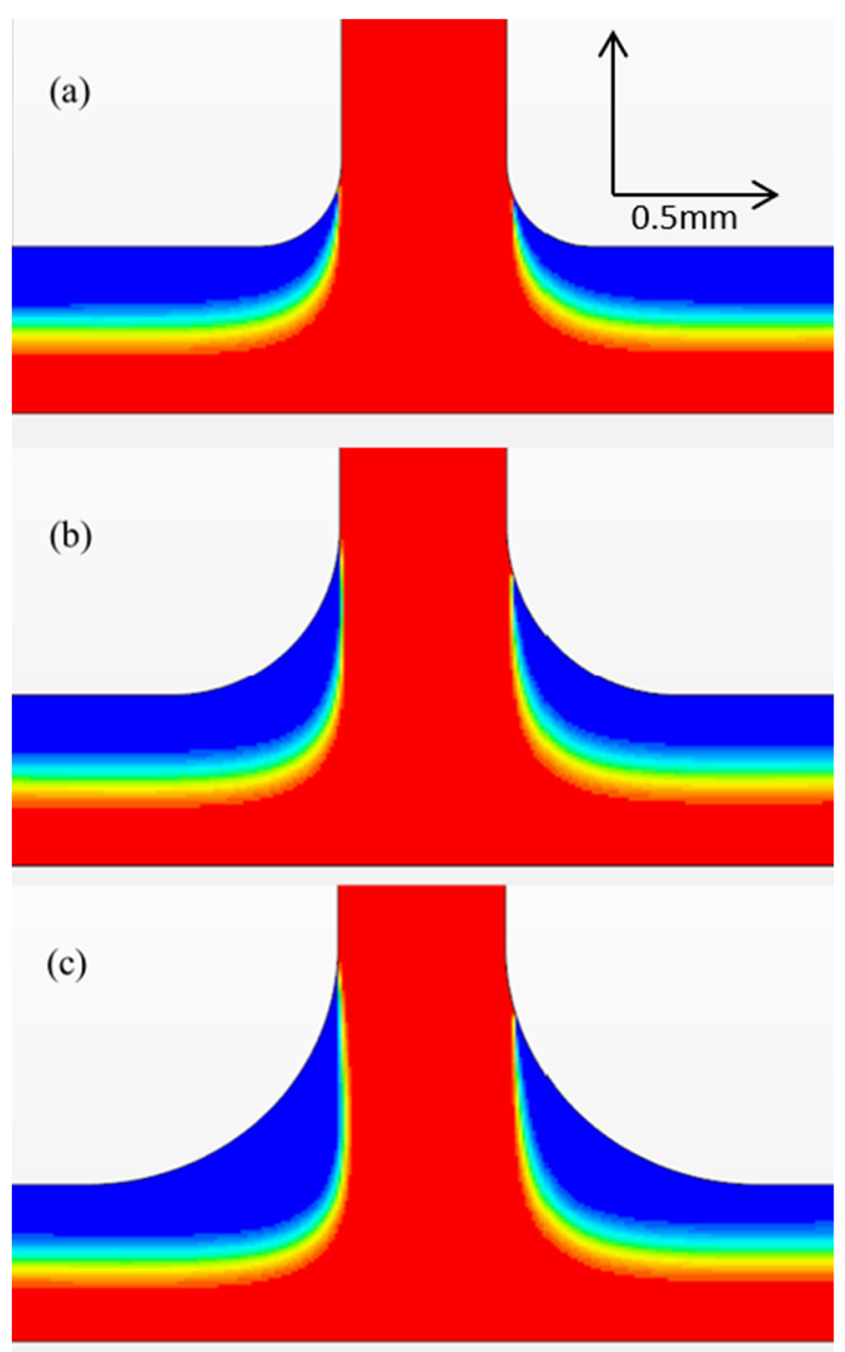

Fig. 10. a Volume Fraction of Electrolyte for R0.25 nozzle at $0.175 \mathrm{1/ \textrm {min }}$ flow rate, $\mathbf{b}$ R0.5 nozzle at $0.175 \mathrm{l} / \mathrm{min}$ flow rate, c R0.75 nozzle at 0.225 $1 /$ min flow rate, all at $\mathrm{t}=1 \mathrm{~s}$

nozzle wall. It is thought that the spikes are fully dominated by air movement away from the fluid flow.

\subsubsection{Electrodynamics and material removal}

From the method outlined in section 2.3.4, the simulated depth profiles were constructed from the current density distributions recorded on the workpiece surface during the simulations. It must be recognised that the simulation for the current density distribution is set up to record the distribution at the instantaneous point in time at the beginning of the machining cycle, as with any material removal the current density distribution will change. This distribution is used as a constant for a two second machining cycle, and therefore, will not fully represent the machining cycle, but will give an indication of the differences between nozzles. In general, all the profiles produced show the expected Gaussian distribution. Current
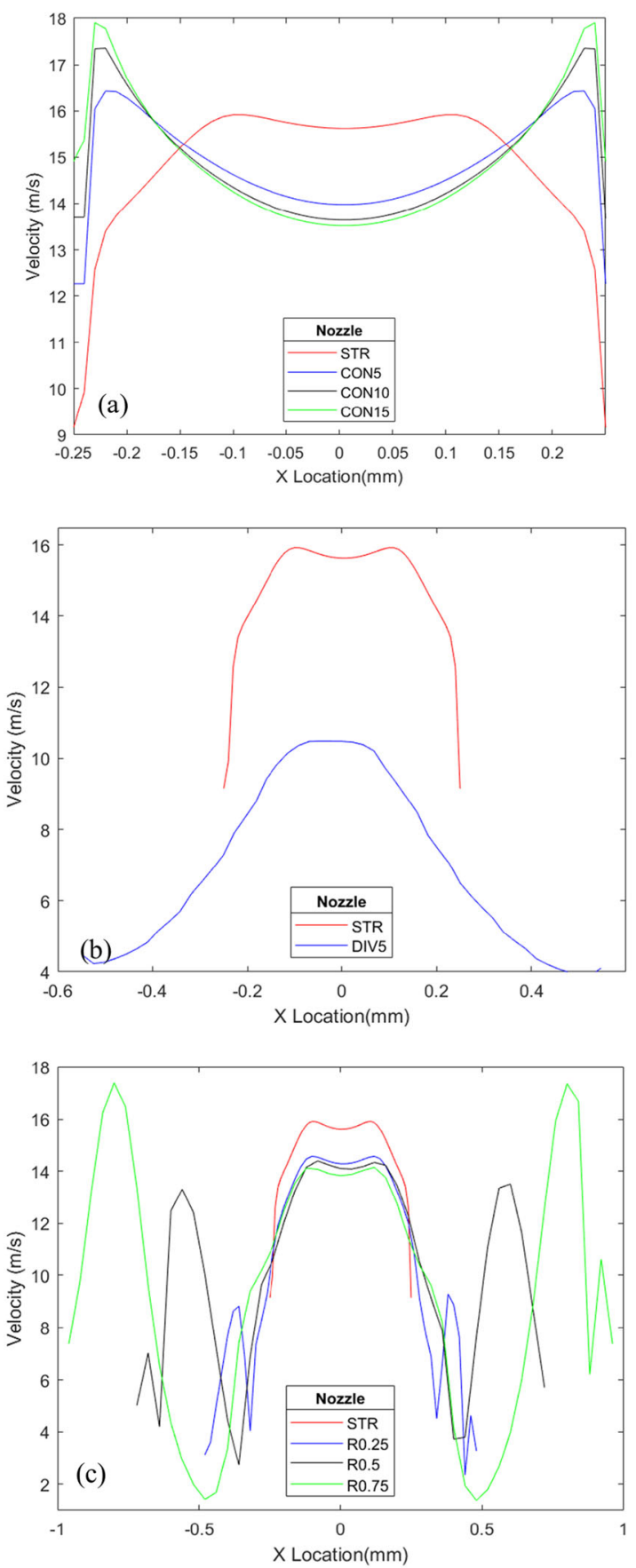

Fig. 11. a Flow Velocity Profiles at nozzle outlets for straight and converging nozzles, b Flow velocity profiles at nozzle outlet for straight and diverging nozzle, $\mathbf{c}$ Flow velocity profiles at nozzle outlet for straight and rounded nozzles. All at $0.175 \mathrm{l} / \mathrm{min}$ flow rate

density distribution is the fundamental driver for material removal in Jet-ECM, with material removal rate being directly proportional to current (Eq. 1). Jet shape and electrolyte conductivity dictate the current distribution on the workpiece by increasing or decreasing the electrical resistivity to areas of the workpiece surface. Although current density distribution is the key parameter for material removal, it in turn is influenced by factors relating to nozzle geometry. 

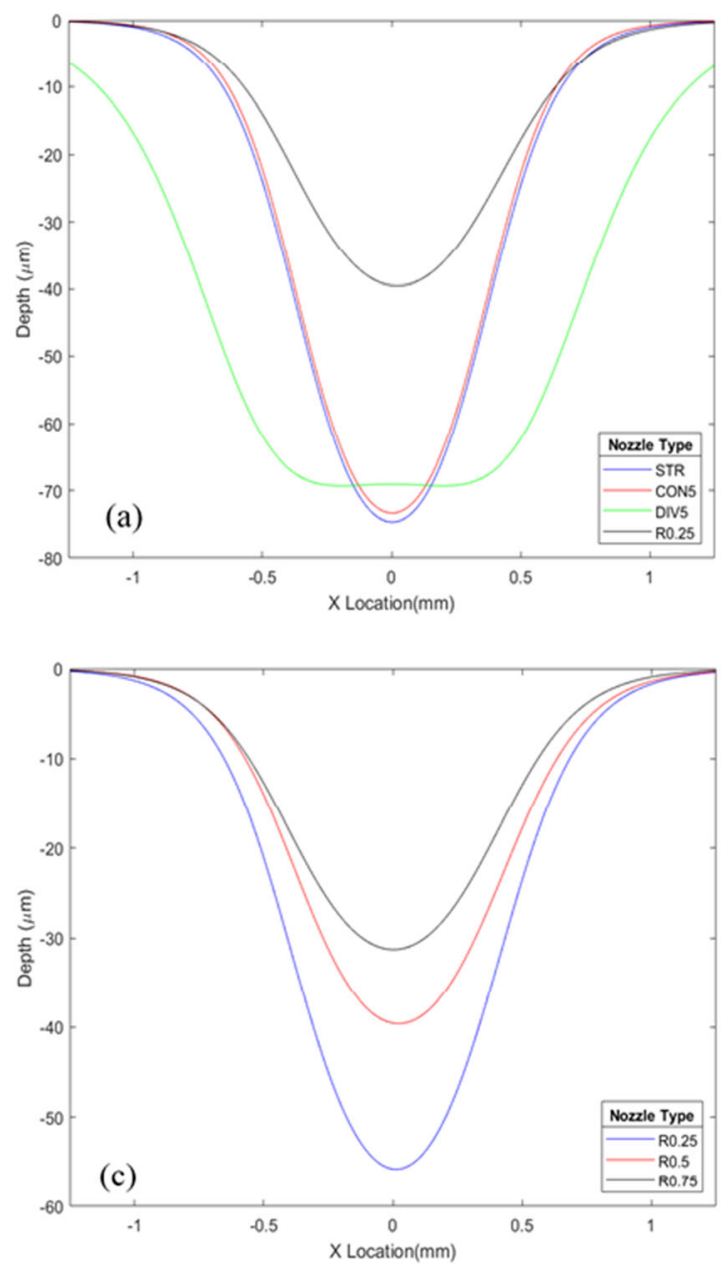

Fig. 12. a Simulated depth profiles for various nozzles at $0.1751 / \mathrm{min}$ flow rate. b Simulated depth profiles for the converging nozzles at $0.175 \mathrm{l} / \mathrm{min}$ flow rate. c Simulated depth profiles for the rounded outlet nozzles at

Figure 12a shows the simulated depth profiles for the straight, CON5, DIV5, and R0.25 nozzles after $2 \mathrm{~s}$ of machining time. As in the experimental results, it can be seen the straight nozzle produces the deepest profile, but only marginally over the CON5 nozzle. The difference in depth between the straight and rounded nozzles was larger in the simulated results than in the experimental results. Whereas in the simulated results the R0.5 nozzle produced a depth $53 \%$ of that achieved by the straight nozzle, with depths of $39.6 \mu \mathrm{m}$ and $74.5 \mu \mathrm{m}$, respectively, at $0.175 \mathrm{l} / \mathrm{min}$ flow rate, the experimental difference showed a difference of less than $10 \mu \mathrm{m}$ at 0.175 $1 / \mathrm{min}$ flow rate. The width profile for all 3 types of nozzle is highly similar in the experimental results, whereas the simulated results showed a narrower profile for the rounded nozzle. The rounded nozzle also produces the shallowest machined profile due to the increased resistance over the gap, however, the width of the straight, converging, and rounded nozzle is highly similar. In the simulation, due to the wider outlet, the diverging nozzle produces a wider machined profile, but with a depth around $7 \mu \mathrm{m}$ less than the
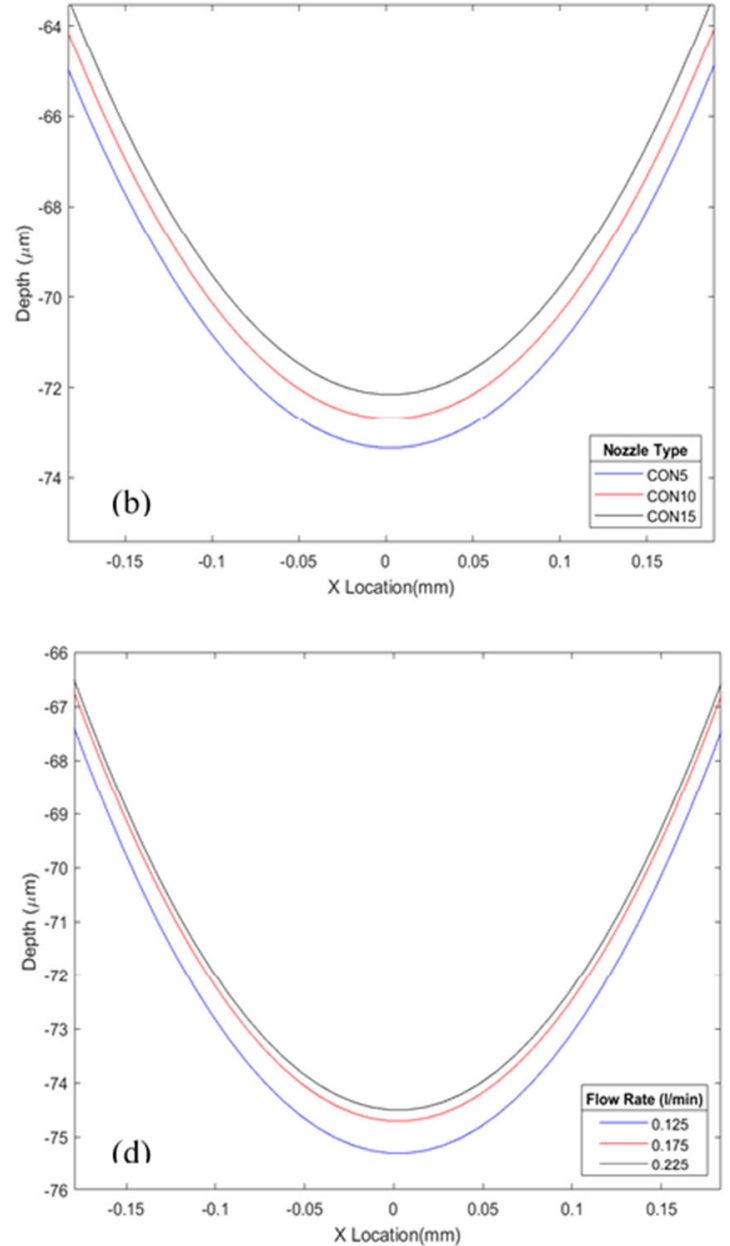

$0.1751 /$ min flow rate. $\mathbf{d}$ Simulated depth profiles for the straight nozzle at varying flow rates

straight nozzle, however, this does not match the performance of the experimental results.

These differences between the simulated and experimental results are believed to be due to the gap resistance being higher in the experimental setup leading to loss of machining efficiency in comparison to the simulated material removal process. The flow from the rounded nozzle may separate from the nozzle wall at a lower point in the experimental trials, and may expand when compared to the straight nozzle, which would be indicated by a wider machined profile from a wider jet area. Stray electrolyte spray from the working area will also alter the resistance across the gap. However, when comparing the simulated results from the 3 rounded outlet nozzles (Fig. 12c) the relationship of machined depth to round dimension follows the same trend as seen in the experimental results. Comparatively, the width of the profile has more variation in the simulated results, with the width reducing with increased round dimension, however, in the experimental results the R0.25 and R0.5 nozzles showing little variation and the R0.75 nozzle showing a lower width. The degree of 
convergence for the converging nozzles had a minor effect on the simulated machined profile, as seen in $12 \mathrm{~b}$ focused on the bottom of the profile. Although the depth and width do decrease with an increasing degree of convergence, the variation
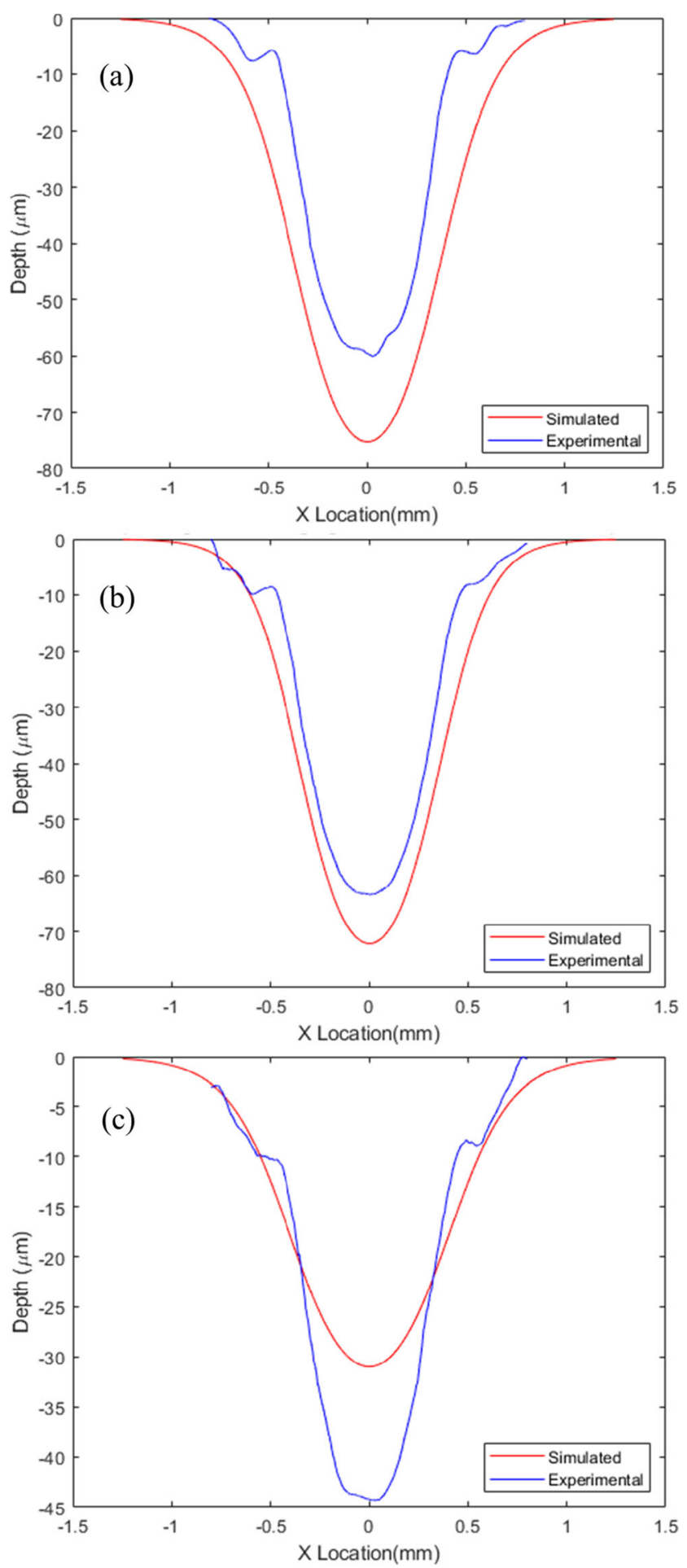

Fig. 13. a Depth profile comparison for straight nozzle at $0.125 \mathrm{l} / \mathrm{min}$ flow rate, b Depth profile comparison for CON15 nozzle at $0.175 \mathrm{l} / \mathrm{min}$ flow rate, $\mathbf{c}$ Depth profile comparison for R0.75 nozzle at $0.125 \mathrm{l} / \mathrm{min}$ flow rate is within $2 \mu \mathrm{m}$, indicating the profile is dominated by the nozzle outlet diameter over the degree of convergence. This variation is much lower than that of the experimental results, which showed a difference of $10 \mu \mathrm{m}$ at the same flow rate of $0.175 \mathrm{l} / \mathrm{min}$. However, contrary to the experimental results, the relationship between nozzle convergence and machined depth shows a decreasing depth with increased convergence. In line with the experimental results the machined pit width shows no variation with changing degree of convergence.

The variation in the dimension of the round on the rounded outlet nozzles produced a more noticeable difference in profile than the variation of convergence (Fig. 12c). Due to the increased gap between the point of flow separation and the workpiece with an increased round, the gap resistance increases and therefore, the machining current drops for a constant voltage. This can be visualised in the decreased depth of the machined profiles. As this change of resistance would be assumed linear with increased distance, the difference between the depths produced by the rounded outlet nozzles would be unexpected if the depth was fully dominated by gap resistance. However, the change in flow profile and minor variations in flow separation are thought to influence the machined profile also.

It can be seen from Fig. 12d that the flow rate has a very small effect on the depth profile produced. Although there is a trend that depth decreases with increased flow rate, matching the experimental results, the variation in depth is within $2 \mu \mathrm{m}$ and in general the profile shows high similarity. This is a trend that is applicable to all the nozzle profiles.

When comparing the simulated profiles to the experimental profiles, for the converging and straight nozzles, the simulation outperformed the experiments in terms of depth and width as represented in Fig. 13a and 13b. For the converging nozzles, the difference was reduced, and the profiles were more closely matched with the increasing convergence size (Fig. 13b).

However, for the rounded outlet nozzles, the experimental results present a deeper machined profile those of the simulation, with the difference increasing with an increased round size (Fig. 13c). This could be due to the difference in the flow profile between the simulation and experiments, with the gap resistance being significantly lower in the experiments than in the simulation. However, as these results do show the nozzle geometry has a significant effect on current distribution and machined profiles, further work is required to develop accurate models encompassing various geometries outside of straight nozzles and assumed flow profiles.

\section{Conclusions}

This study set out to investigate the effect of nozzle geometry on the material removal characteristics of Jet-ECM. As 
previously mentioned, current density distribution directly influences the material removal rate, and is influenced by both the nozzle tip geometry, and the jet shape and flow profile on the workpiece surface, each having an effect on the flow of current between the nozzle and the workpiece. From both the simulated and experimental results, although the nozzles studied all share a minimum diameter of $0.5 \mathrm{~mm}$, the variation in geometry does have a significant effect on the profiles produced through Jet-ECM by altering the current density distribution through jet shape and flow. Variations of over $23 \mu \mathrm{m}$ in depth between nozzle designs. The results indicate that:

- Contrary to the simulated results, the converging nozzles with CON10 and CON15 nozzles produce a deeper machined profile $(61.37 \mu \mathrm{m}$ and $63.36 \mu \mathrm{m}$, respectively) than that of the straight nozzle $(58.7 \mu \mathrm{m})$, with the CON5 nozzle showing a shallower profile than the straight nozzle in experimental conditions $(53.57 \mu \mathrm{m})$.

- In comparison to the straight nozzle, the largest percentage increase in depth was found in the CON10 nozzle at $0.2251 / \mathrm{min}$ flow rate with an increase of $9.7 \%$. However, the CON15 nozzle produced more consistent depth increases than that of the CON10 nozzle, with a percentage increase of depth over the straight nozzle of $8.5 \%, 7.9 \%$, and $9.3 \%$ at 0.125 , 0.175 , and $0.225 \mathrm{l} / \mathrm{min}$ flow rates, respectively.

- The diverging nozzle produced an erratic machined profile due to fluctuations in the flow within the nozzle producing a none-symmetrical flow pattern. This highlights that divergent nozzle designs effect the stability of the flow, and therefore current distribution, resulting in unstable machining.

- Placing a rounded feature on the nozzle outlet decreases the machined profile depth with an increasing size of the rounded feature, with depths of $56.63 \mu \mathrm{m}, 51.31 \mu \mathrm{m}$, and $40.16 \mu \mathrm{m}$ for the $0.25 \mathrm{~mm}, 0.5 \mathrm{~mm}$, and $0.75 \mathrm{~mm}$ rounds, respectively at $0.175 \mathrm{l} / \mathrm{min}$ flow rate. Machining current decreases with increased round radius at a constant voltage by over $34 \%$ between the R0.25 and R0.75 nozzles.

- Variations in the nozzle geometry showed little effect on the machined profile width in comparison to the depth, with the nozzle outlet diameter being the driving feature in machined width.

- Both simulated and experimental results show that increasing the flow rate has a negative effect on the machined profile depth, but within a range of $4 \mu \mathrm{m}$ for the range of flow rates studied. It is recommended that further trials are performed to prove this relationship, as the range is small enough to be due to experimental variations.

- Generally, the converging nozzles had a reduced flow pressure than the straight nozzle at a constant flow rate, apart from the CON10 nozzle. The rounded outlet nozzle had little pressure variation with increasing round radius at 0.125 and $0.175 \mathrm{l} / \mathrm{min}$ flow rate, but showed variation at $0.225 \mathrm{l} /$ min flow rate indicating varying flow profiles at higher flow rates. Machining with lower pressure with no detriment to machined depth is beneficial for machining delicate components as well as reducing the load on the circulation system.

As the majority of Jet-ECM studies have been performed with a straight, cylindrical nozzle, this study shows that there is a benefit to developing the nozzle geometries to improve the control and depth achieved of the material removal process. By simply modifying the nozzle geometry, an increase in machined depth of up to $9.7 \%$ has been realised over the traditional straight nozzle without altering any machining parameters. By considering the results of this study, as the machined profile varies with nozzle geometry, and considering fellow studies into nozzle tip geometry and the impact of flow distribution on the material removal in Jet-ECM there is an opportunity to design nozzles to produce specific profiles as an alternative to controlling the machining parameters and machine path for surface modification. These designs will ultimately give more control over the Jet-ECM process, enabling the technology to be considered as an industrial process. This does not just require consideration of nozzle tip geometries as previously studied, but the geometry of the nozzle channel itself, and a combination of both aspects. As the results show the nozzle geometries have a large impact on pit depth, width, and shape, nozzle geometry needs to be considered for machining stability and repeatability regarding depth and localisation for Jet-ECM as a manufacturing process. For further development of the nozzles, a wider range of nozzle feature dimensions need to be investigated, such as a larger range of nozzle channel convergence and minimum nozzle channel diameters.

Accurate simulation of the material removal process will aid the development of nozzles and with the design of the machining process to machine specific geometries without the need for estimation from experimental trials, saving on nozzle manufacture and costs associated with said trials. The model should be developed to produce simulations that more accurately predict the experimental process with an aim of better predicting material removal profiles of nozzle geometries by incorporating current efficiencies and time dependent studies such as that by Hackert-Oschätzchen et al. [27]. It has been seen that the nozzle geometries affect the flow pressure and shape, and as such nozzle design needs to be carefully considered to produce the best flow and current distribution for Jet-ECM purposes in consideration of the work by Wang et al. [14].

Acknowledgements The author would like to acknowledge the support of Blueacre Technology for their sponsorship in this research, as well as the support of the DTP scholarship through ESPRC.

Authors contributions Thomas Kendall: Conceptualization, Methodology, Software, Validation, Formal Analysis, Investigation, Data Curation, Writing - Original and Draft, Writing Review \& Editing, Visualisation. Paulo Bartolo: Writing Review \& Editing, 
Supervision, Project administration, Visualisation. Carl Diver: Conceptualization, Methodology, Writing Review \& Editing, Visualisation, Supervision David Gillen: Project administration, Writing Review \& Editing, Supervision

Funding The author would like to acknowledge the support of Blueacre Technology for both their financial assistance and sponsorship in this research, as well as the support of the DTP scholarship through ESPRC.

Data availability The authors confirm that the data supporting the findings of this study are available within the article. The raw data are available from the corresponding author upon a request.

\section{Declarations}

Competing interests The authors declare no competing interests.

Ethical approval The work contains no libellous or unlawful statements, does not infringe on the rights of others, or contains material or instructions that might cause harm or injury.

\section{Consent to participate Not applicable.}

Consent to publish The editor has the authors consent to publish.

Open Access This article is licensed under a Creative Commons Attribution 4.0 International License, which permits use, sharing, adaptation, distribution and reproduction in any medium or format, as long as you give appropriate credit to the original author(s) and the source, provide a link to the Creative Commons licence, and indicate if changes were made. The images or other third party material in this article are included in the article's Creative Commons licence, unless indicated otherwise in a credit line to the material. If material is not included in the article's Creative Commons licence and your intended use is not permitted by statutory regulation or exceeds the permitted use, you will need to obtain permission directly from the copyright holder. To view a copy of this licence, visit http://creativecommons.org/licenses/by/4.0/.

\section{References}

1. Schubert A, Hackert-Oschätzchen M, Martin A, Winkler S, Kuhn D, Meichsner G, Zeidler H, Edelmann J (2016) Generation of Complex Surfaces by Superimposed Multidimensional Motion in Electrochemical Machining. Proc CIRP 42:384-389. https://doi. org/10.1016/j.procir.2016.02.216

2. Hackert-Oschätzchen $\mathrm{M}$, Meichsner G, Zinecker M, Martin A, Schubert A (2012) Micro machining with continuous electrolytic free jet. Precis Eng 36(4):612-619. https://doi.org/10.1016/j. precisioneng.2012.05.003

3. Natsu W, Ikeda T, Kunieda M (2007) Generating complicated surface with electrolyte jet machining. Precis Eng 31(1):33-39. https:// doi.org/10.1016/j.precisioneng.2006.02.004

4. Kunieda M, Mizugai K, Watanabe S, Shibuya N, Iwamoto N (2011) Electrochemical micromachining using flat electrolyte jet. CIRP Ann 60(1):251-254. https://doi.org/10.1016/j.cirp.2011.03. 022

5. Kawanaka T, Kunieda M (2015) Mirror-like finishing by electrolyte jet machining. CIRP Ann 64(1):237-240. https://doi.org/10. 1016/j.cirp.2015.04.029
6. Zhao Y, Kunieda M (2019) Investigation on electrolyte jet machining of threedimensional freeform surfaces. Precis Eng 60:42-53. https://doi.org/10.1016/j.precisioneng.2019.06.009

7. Mitchell-Smith J, Speidel A, Gaskell J, Clare AT (2017) Energy distribution modulation by mechanical design for electrochemical jet processing techniques. Int J Mach Tools Manuf 122:32-46. https://doi.org/10.1016/j.jimachtools.2017.05.005

8. Mitchell-Smith J, Speidel A, Clare AT (2018) Transitory electrochemical masking for precision jet processing techniques. J Manuf Process 31:273-285. https://doi.org/10.1016/j.jmapro.2017.11.028

9. Mitchell-Smith J, Bisterov I, Speidel A, Ashcroft I, Clare AT (2019) Direct-writing by active tooling in electrochemical jet processing. Manuf Lett 19:15-20. https://doi.org/10.1016/j.mfglet. 2019.01.001

10. Liu Y, Qu N (2020) Obtaining high surface quality in electrolyte jet machining TB6 titanium alloy via enhanced product transport. J Mater Process Technol 276:116-381

11. Chen XL, Dong BY, Zhang CY, Luo HP, Liu JW, Zhang YJ (2019) Electrochemical direct-writing machining of micro-channel array. J Mater Process Technol 265:138-187

12. Luo J, Fang X, Zhu D (2020) Jet electrochemical machining of multi-grooves by using tube electrodes in a row. J Mater Process Technol 283:116-705. https://doi.org/10.1016/j.jmatprotec.2020. 116705

13. Paul R, Hackert-Oschätzchen M, Danilov I, Zanjani MY, Schubert A (2019) 3D Multiphysics Simulation of Jet Electrochemical Machining of Intersecting Line Removals. Proc CIRP 82:196201. https://doi.org/10.1016/j.procir.2019.04.154

14. Wang X, Qu N, Fang X (2019) Reducing stray corrosion in jet electrochemical milling by adjusting the jet shape. J Mater Process Technol 264:240-248

15. Tafreshi HV, Pourdeyhimi B, Holmes R, Shiffler D (2003) Simulating and Characterizing Water Flows Inside Hydroentangling Orifices. Text Res J 73(3):256-262. https://doi. org/10.1177/004051750307300310

16. Begenir A, Tafreshi HV, Pourdeyhimi B (2004) Effect of Nozzle Geometry on Hydroentangling Water Jets: Experimental Observations. Text Res J 74(2):178-184. https://doi.org/10.1177/ 004051750407400215

17. Diver C, Atkinson J, Helml HJ, Li L (2004) Micro-EDM drilling of tapered holes for industrial applications. J Mater Process Technol 149(1-3):296-303. https://doi.org/10.1016/j.jmatprotec.2003.10. 064

18. Ghassemieh E, Versteeg H, Acar M (1989) The effect of nozzle geometry on the flow characteristics of small water jets. In: ARCHIVE Proceed ings of the Institution of Mechanical Engineers Part C Journal of Mechanical Engineering Science, $p 220$

19. Tafreshi HV, Pourdeyhimi B (2004) Simulating Cavitation and Hydraulic Flip Inside Hydroentangling Nozzles. Text Res J 74(4): 359-364. https://doi.org/10.1177/004051750407400413

20. Anantharamaiah N, Tafreshi HV, Pourdeyhimi B (2006) Numerical Simulation of the Formation of Constricted Waterjets in Hydroentangling Nozzles. Chem Eng Res Des 84(3):231-238. https://doi.org/10.1205/cherd.05077

21. McCarthy MJ, Molloy NA (1974) Review of stability of liquid jets and the influence of nozzle design. Chem Eng J 7(1):1-20. https:// doi.org/10.1016/0300-9467(74)80021-3

22. YONEDA K, KUNIEDA M (1995) Numerical Analysis of Cross Sectional Shape of Micro-Indents Formed by the Electrochemical Jet Machining (ECJM). https://doi.org/10.2526/jseme.29.62_1

23. Pajak PT, Silva AKMD, McGeough JA, Harrison DK (2004) Modelling the aspects of precision and efficiency in laser-assisted jet electrochemical machining (LAJECM). J Mater Process Technol 149(1-3):512-518. https://doi.org/10.1016/j.jmatprotec. 2003.10.055 
24. Hackert M, Meichsner G, Schubert A (2008) Simulation of the Shape of Micro Geometries generated with Jet Electrochemical Machining, in COMSOL Conference, $\mathrm{p} 4$

25. Zhang H, Xu J (2010) Modeling and Experimental Investigation of Laser Drilling with Jet Electrochemical Machining. Chin J Aeronaut 23(4):60241-60248

26. Hackert M, Meichsner G, Jahn SF, Schubert A (2010) Investigating the influence of dynamic jet shapes on the jet electrochemical machining process. In Proc. of the European COMSOL Conference

27. Hackert-Oschätzchen M, Paul R, Martin A, Meichsner G, Lehnert N, Schubert A (2015) Study on the dynamic generation of the jet shape in Jet Electrochemical Machining. J Mater Process Technol 223:240-251. https://doi.org/10.1016/j.jmatprotec.2015.03.049

28. Hackert-Oschätzchen M, Paul R, Kowalick M, Martin A, Meichsner G, Schubert A (2015) Multiphysics Simulation of the Material Removal in Jet Electrochemical Machining. Proc CIRP 31:197-202. https://doi.org/10.1016/j.procir.2015.03.098

29. Ming W, Zhongninga G, Junfeng H, Xiaolei C (2018) Modeling and Simulation of the Material Removal Process in Electrolyte Jet Machining of Mass Transfer in Convection and Electric Migration. Proc CIRP 68:488-492. https://doi.org/10.1016/j.procir.2017.12. 079

30. Hackert-Oschätzchen M, Paul R, Schubert A (2019) Multiphysics Simulation of Oxide Layer Growth in Localized Anodization of Aluminum Applying a Free-Surface Electrolyte Jet. Proce CIRP 82:243-248. https://doi.org/10.1016/j.procir.2019.04.035

31. Wang MH, Tong WJ, Qiu GZ, Xu XF, Speidel A, Mitchell-Smith J (2019) Multiphysics study in air-shielding electrochemical micromachining. J Manuf Process 43:124-135. https://doi.org/10. 1016/j.jmapro.2019.05.019

32. Lide DR (1995) CRC handbook of chemistry and physics. In: L. DR (ed) CRC handbook of chemistry and physics, vol 75. CRC Press, Boca Raton, p 75

33. Mcgeough JA (1974) Principles of Electrochemical Machining, in Principles of Electrochemical Machining. Chapman and Hall Ltd, London

34. Norton JD, Pederson LR (1994) Ammonia in simulated Hanford double-shell tank wastes: Solubility and effects on surface tension. https://doi.org/10.2172/10192447

35. Isono T (1984) Density, viscosity, and electrolytic conductivity of concentrated aqueous electrolyte solutions at several temperatures. Alkaline-earth chlorides, lanthanum chloride, sodium chloride, sodium nitrate, sodium bromide, potassium nitrate, potassium bromide, and cadmium nitrate. J Chem Eng Data 29(1):45-52. https://doi.org/10.1021/je00035a016

36. Touloukian YS, Saxena SC, Hestermans P (1975) Viscosity, in Thermophysical proper ties of matter the TPRC data series, vol 11. IFI/Plenum

37. Westaway EG, Reedman BM (1970) Cameron Hydraulic Data; A handy reference on the subject of hydraulics and steam. In: Cameron Hydraulic Data; A handy reference on the subject of hydraulics and steam, vol 4. Ingersoll Rand, New Jersey, pp 688-693. https://doi.org/10.1128/jvi.4.5.688-693.1969

Publisher's note Springer Nature remains neutral with regard to jurisdictional claims in published maps and institutional affiliations. 